\title{
Work Breakdown Structure Guide
}

\section{U.S. Department of Energy} Assistant Secretary, Management and Administration Office of Project and Facilities Management Washington, D.C. 20585

February 6, 1987

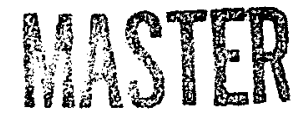

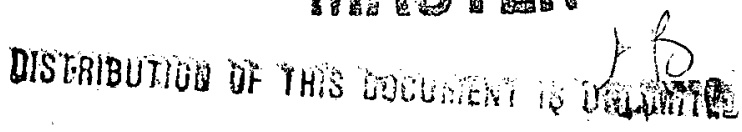




\section{DISCLAIMER}

This report was prepared as an account of work sponsored by an agency of the United States Government. Neither the United States Government nor any agency Thereof, nor any of their employees, makes any warranty, express or implied, or assumes any legal liability or responsibility for the accuracy, completeness, or usefulness of any information, apparatus, product, or process disclosed, or represents that its use would not infringe privately owned rights. Reference herein to any specific commercial product, process, or service by trade name, trademark, manufacturer, or otherwise does not necessarily constitute or imply its endorsement, recommendation, or favoring by the United States Government or any agency thereof. The views and opinions of authors expressed herein do not necessarily state or reflect those of the United States Government or any agency thereof. 


\section{DISCLAIMER}

Portions of this document may be illegible in electronic image products. Images are produced from the best available original document. 


\section{FOREWORD}

Utilization of the work breakdown structure (WBS) technique is an effective aid in managing Department of Energy (DOE) programs and projects. The technique provides a framework for project management by focusing on the products that are being developed or constructed to solve technical problems. It assists both DOE and contractors in fulfilling their management responsibilities.

This document provides guidance for use of the WBS technique for product oriented work identification and definition. It is one in a series of policy and guidance documents supporting DOE's project management system. Appendix A provides a complete listing of related documentation.

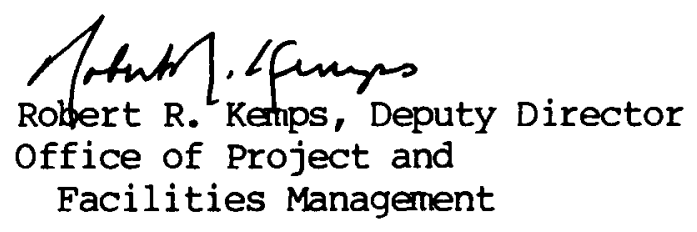


TABLE OF CONTENTS

Page

I. INTRODUCTION

A. PURPOSE I-I

B. SCOPE

$I-1$

C. BACKGROUND

$\mathrm{I}-1$

D. SUMMARY OF DEVELOPMENT AND USE

$I-2$

E. REFERENCES

$I-2$

F. ORGANIZATION OF GUIDE

$I-2$

II. TERMINOLOGY

A. GENERAL DESCRIPTION II-1

B. WBS TYPES

II -1

1. Project Summary WBS (PSWBS) II-1

2. Contract WBS (CWBS) II -3

$\begin{array}{ll}\text { C. DEFINITION OF TERMS } & \text { II }-3\end{array}$

III. DEVELOPMENT AND MAINTENANCE OF A WBS

A. GENERAL

I I I -

B. PROJECT OFFICE RESPONSIBILITIES

II I -1

1. Prepare PSWBS

2. Select Elements for Solicitation

I I I-1

3. Conduct Evaluation

4. Select Contractor; Negotiate Contract

III-2 and CWBS Changes

III -2

5. Approve CWBS; Award Contract

II I -3

6. Revise PSWBS As Required

III -3

7. Maintain PSWBS

III -3

III -3

C. CONTRACTOR RESPONSIBILITIES III-3

1. Extend CWBS and Submit III-3

2. Negotiate Changes III-3

3. Maintain CWBS

III -4

D. DEVELOPMENT CONSIDERATIONS III-4

1. Compatibility of CWBSs with PSWBS III-4

2. Compatibility with Internal Organization Structure and Management Systems II I-4

3. Correlation with Other Requirements (Project/Contract)

II I-4

4. Number of Levels (Project/Contract) III-4 
5. All Inclusive (Products/Participants)

III-6

6. Change Control (Within Phase/Between Phases)

E. TECHNIQUES FOR WBS DEVELOPMENT

1. Coding

III-8

2. Diagrams

III-8

3. Dictionary

III -9

4. Checklists

III-9

F. DEVELOPMENT CAVEATS

1. Prior WBS Basis

III -11

2. Nonproduct Elements

III -12

3. Functional Elements

I I I -12

IV. USE OF THE WORK BREAKDOWN STRUCTURE

A. GENERAL

IV-1

B. TECHNICAL MANAGEMENT

IV-1

1. Specification Tree

IV-1

2. Configuration Management

IV -3

3. Integrated Logistic Support (ILS)

IV-3

4. Test and Evaluation

IV-3

C. WORK IDENTIFICATION AND ASSIGNMENT

IV -4

D. SCHEDULE MANAGEMENT

IV -4

1. Plans

2. Revisions

IV-4

3. Status

IV-5

IV -5

E. COST MANAGEMENT

IV-5

1. Cost Estimating

IV-5

2. Budgeting

IV-6

3. Accounting

IV-6

F. PERFORMANCE MEASUREMENT

IV-7 
A. OTHER DOE STRUCTURES AND PROCESSES AND THEIR Al-1 RELATIONSHIP TO THE WBS

\section{APPENDICES}

A. WORK BREAKDOWN STRUCTURE GUIDE REFERENCE DOCUMENTS A-1

B. TYPICAL PROJECT SUMMARY WORK BREAKDOWN STRUCTURES B-1

1. Nuclear Generating Plant B-2

2. Fuel Processing Plant B-3

3. Test Facility B-4

4. Test Reactor Modification Project B-5

5. Accelerator Project at an Existing site B-6

C. WORK BREAKDOWN STRUCTURE DICTIONARY C-1

1. Example - Work Breakdown Structure Dictionary
Part I - Index

2. Example - Work Breakdown Structure Dictionary
Part II - Element Definition

D. UNIFORM REPORTING SYSTEM REPORTING REQUIREMENTS CHECKLIST D I

1. DOE Form 1332.1 D-2

E. DEVELOPMENT OF A PROJECT SUMMARY WBS E-1 
Figure 1 Proposed Work Breakdown Structure for I-3 Strategic Petroleum Reserve

Figure 2 Typical Project Work Breakdown Structure (Partial)

I I-2 with Contract WBS (s)

Figure 3 DOE and Contractor Responsibilities

II I -3

Figure 4 Integration of Contract WBS with Organization Structure

Figure 5 Technical - Schedule - Cost Integration

Figure 6 Plot Plan with Primary Level Cost Codes

Figure 7 Integration of Contract WBS and Secondary Level Cost Codes

Figure 8 Project Cost Codes for Construction (Matrix)

Figure 9 Project Cost Estimate for Concrete

Figure 10 Project Accounting Cost Element Structure Example

Figure 11 Construction Specifications Institute (CSI)

Figure 13 Construction Project Data Sheet - Construction 
CHAPTER I

INTRODUCTION

A. PURPOSE

This document provides guidance on the development and use of the work breakdown structure (WBS) technique. It describes the WBS types, their preparation, and their effective use for organizing, planning, and controlling projects and contracts managed by the Department of Energy (DOE), and their relationship to other DOE control structures and processes.

B. SCOPE

These WBS guidelines are to be used for varied work efforts including; research, development, construction, demonstration, test and evaluation, operation, and production. The products of these efforts may be real estate, hardware, software, data, or service elements, alone or in combination. In accordance with DOE Order $4700 . \mathrm{X}$, PROJECT MANAGEMENT SYSTEM, a WBS is mandatory for DOE major system acquisitions and major projects, and will be used for other projects to the extent practicable. A WBS is required when the DOE Cost and Schedule Control Systems Criteria are applied on a contract.

\section{BACKGROUND}

As DOE projects evolve from conceptual formulation through developmental engineering, design, construction, and operation the function of management is to plan and direct project activities toward the achievement of program goals. These program goals are developed from DOE mission needs, and are in turn expanded into specific project objectives. These project objectives are then translated into plans which assign tasks to organizational elements responsible for execution.

Projects are born out of the need to solve technical problems. One of the most important functions of project management, therefore, is to apply resources to solve these technical problems. Solving the technical problems results in satisfying the program goals and mission needs. This requires explicit, quantitative definition of the techniçal objectives, thereby providing the planning base for the entire project. All resources applied to the project over time including manpower, materials, equipment, overhead, and thus dollars, are aimed at satisfying the project's technical objectives. Project management seeks to minimize the use of the resources in accomplishing the objectives.

Satisfying the technical objectives of a project is not achieved simply by the successful completion of final: test/checkout of the completed system. It is achieved incrementally through the successful solution of detail technical problems for -real estate, hardware, software, data, and service elements of increasing scope; e.g., component, subassembly, subsystem, and system, each of which may interface with other elements. A structure which logically defines the relationships of the work products or elements to 
each other and to the total system is required to provide a framework for specifying their technical objectives and for planning and controlling application of the resources needed to solve the technical problems inherent in satisfying the objectives. The WBS is the preferred framework.

D. SUMMARY OF DEVELOPMENT AND USE

A WBS is developed by first identifying the project end item or system to be structured, and then successively subdividing it into increasingly detailed and manageable subsidiary work products or elements. Most of these products are the direct result of work; e.g., assemblies, subassemblies, components, while others are simply the aggregation of selected products into logical sets for management control purposes; e.g., buildings and utilities. In either case, the subsidiary work product has its own set of technical goals and objectives which must be met in order for the entire project to satisfy its technical objectives. Detailed tasks which must be performed to satisfy the subsidiary work product goals and objectives are then identified and defined for each work product or WBS element on which work will be performed.

Because of the technical objectives that must be satisfied by a completed WBS element, completion of the element is an event that is both measurable and verifiable by persons; e.g., quality assurance, independent of the person(s) responsible for its completion. Because of the incrementally verifiable nature of WBS element/product completion, the WBS provides a solid basis for technical, schedule, and cost plans and status. No other structure; e.g., code of accounts, functional organization, budget and reporting (B\&R), cost element; satisfactorily provides an equally solid basis for incremental project performance assessment.

Figure 1 is a proposed WBS for a multiple site project, the Strategic Petroleum Reserve. Each element in the structure has defined technical objectives, so that when incorporated into the entire system, all technical objectives of the project will be satisfied. These defined technical objectives include such items as capacities, reliability, response time, delivery rates, etc.

E. REFERENCES

Appendix A lists relevant orders, information pamphlets, and guides.

F. ORGANIZATION OF GUIDE

Following the Introduction in Chapter I, Chapter II describes WBS types and defines basic WBS terms. Chapter III discusses development and maintenance of the Project Sumary WBS and the contract WBS(s) and describes the related techniques for preparing the WBS coding, the WBS diagrams and a WBS Dictionary, and provides a checklist for preparers and evaluators. Chapter IV discusses use of the WBS for technical, schedule, and cost control. The relationship of the WBS to other DOE structures and processes is discussed in Attachment A. 


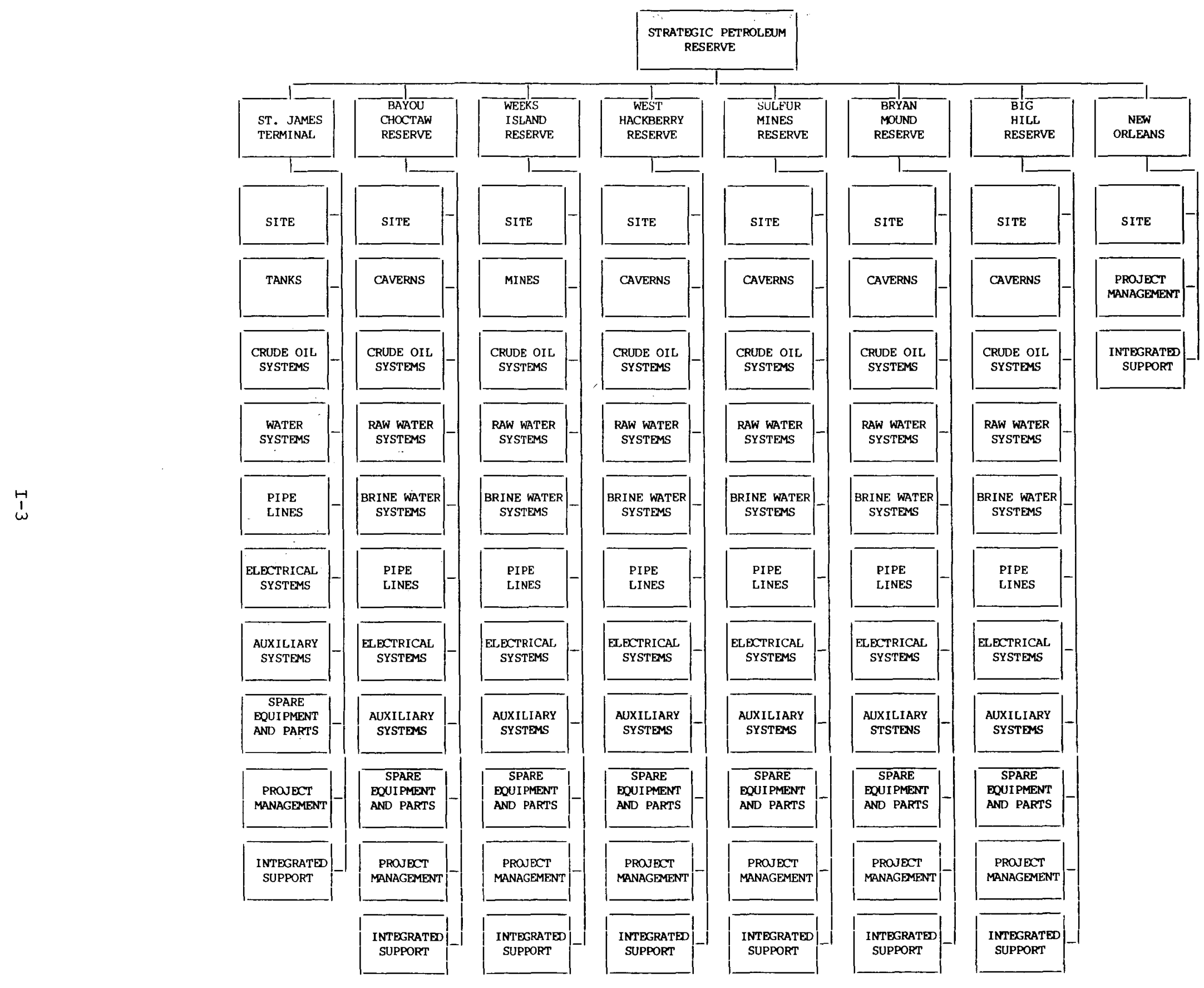

Figure 1. Proposed work Breakdown Structure for Strategic Petroleum Reserve 
CHAPTER II

TERMINOLOGY

A. GENERAL DESCRIPTION

Work is effort performed by people to transform or create products to solve identified technical problems in order to verifiably meet specified technical objectives. Just as the organization structure hierarchically structures the people who perform work, so the WBS hierarchically structures the products and subproducts to be produced and on which the people work. Real estate products that result from work include sites, land, buildings, structures, utilities, etc. Hardware products may be reactor systems, pumps, computer systems, steam generators, components, etc.; software products may be computer programs and documentation, equipment operator manuals, system procedures, etc.; data products may be technical reports, studies, management data, etc.; service products may be project support, project management, systems engineering, configuration management, etc. WBS elements depict work products in a manner in which technical accomplishment can be incrementally verified and measured and provides the conceptual framework for integrated planning and control of the work. Service work; e.g., project management; benefits all real estate, hardware, software, and data products and subproducts in indeterminable proportion. From a management control standpoint such work is essentially indirect to the real estate, hardware, software, and data products, but direct to the contract/project. It is usually desirable that indirect work that does not contribute directly to production of the end product and its components be minimized; thus, service elements should be kept to a minimum in the WBS. Figure 2 illustrates the WBS concept applied to a single site project. Elements of both the Project Summary Work Breakdown structure and the Contract Work Breakdown Structure are shown.

B. WBS TYPES

DOE employs a Project Sumary WBS and a Contract WBS applied to a single site project.

1. Project Summary WBS (PSWBS)

The PSWBS is the structure that encompasses an entire project at a summary level. The PSWBS usually consists of three levels of product with associated work definition and is used as a take-off point for individual contractors to develop their contract work breakdown structure (CWBS). Appendix B includes an example PSWBS for a Nuclear Generating Plant, a Fuel Processing Plant, a Test Facility, a Test Reactor Modification Project, and an Accelerator Project at an existing site. The upper three levels of the PSWBS would typically be defined as follows:

a. Level 1. Level 1 is the entire project; for example, the Waste Isolation Pilot Plant, the Fusion Materials Irradiation Test Facility, or the Strategic Petroleum Reserve. 


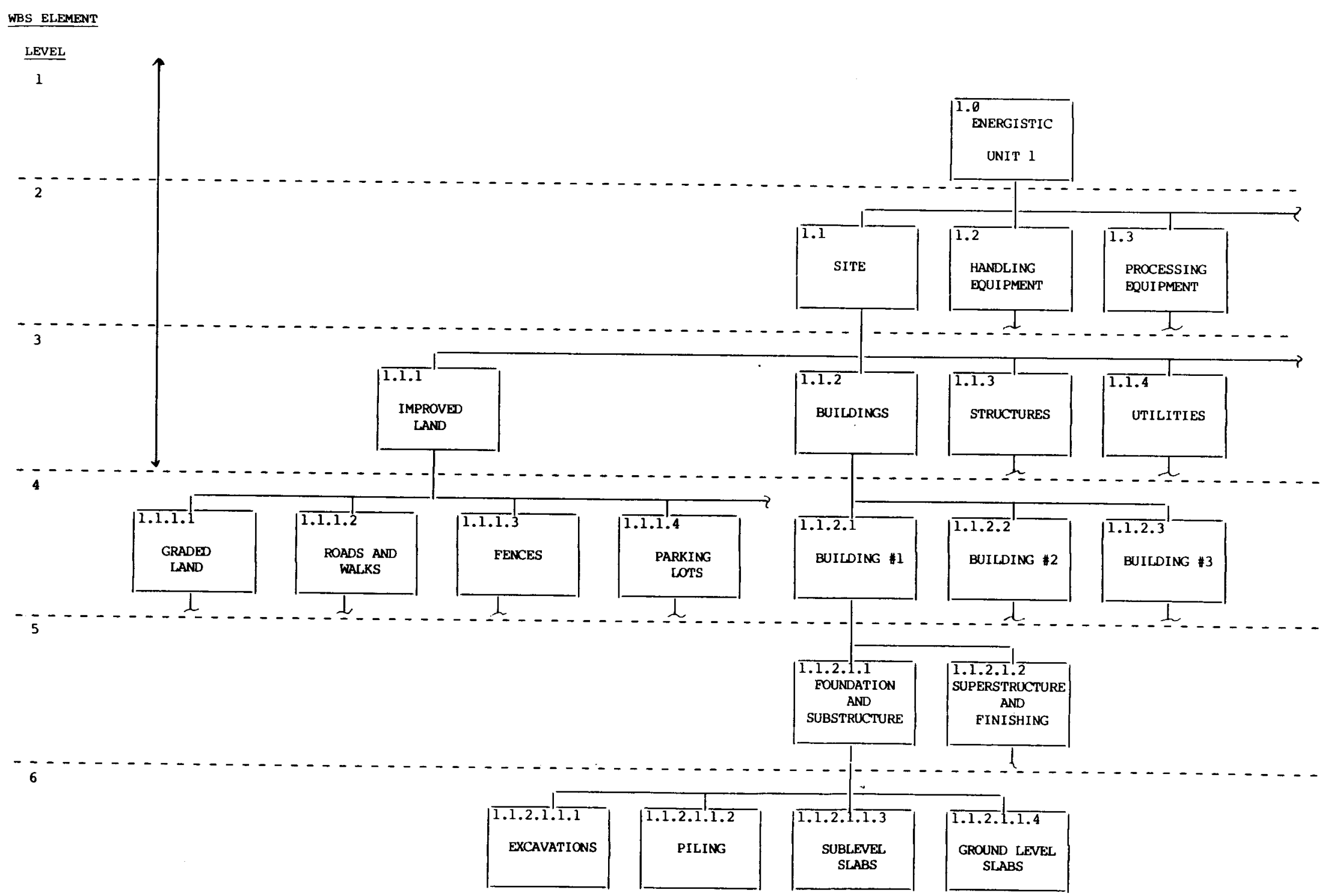

Figure 2. Typical Project Summary Work Breakdown Structure (Partial) With Contract WBS(s) 
b. Level 2. Level 2 elements are the major product segments or subsections of the total project. For example, level 2 of the PSWBS for the Weldon Springs Storage Site Remedial Action Project (WSSRAP) defines the major segments of the project effort; i.e., Quarry, Raffinate Pits, Vicinity Properties, Chemical Plant, Support Facilities, and Project Integration. Another example is the Strategic Petroleum Reserve, where level 2 of the PSWBS identifies the product acquired at each of several locations which make up the total project; i.e., St. James Terminal, Bayou Choctaw Reserve, Weeks Island Reserve, West Hackberry Reserve, Sulfur Mines Reserve, Bryan Mound Reserve, Big Hill Reserve, and New Orleans (Project Support). Level 2 elements for a project located at a single location should also define the primary products or product groups which make up the project. For example, level 2 of the PSWBS for the Advanced Toroidal Facility (ATF) defines Device Systems, Interface Systems, and Project Management.

c. Level 3. Level 3 contains definable components, or subsets, of the level 2 major product segments. For example, level 3 of the PSWBS for the Strategic Petroleum Reserve under the West Hackberry site identifies major products to be acquired at West Hackberry; i.e., Site, Caverns, Crude Oil Systems, Raw Water Systems, Brine Water Systems, Pipelines, Electrical Systems, Auxiliary Systems, Spares, and Project Management and Support. Continuing with the example of the ATF, level 3 under the level 2 Device Systems element includes Helical Field Coils, Inner Vertical Field Coils, Outer Vertical Field Coils, Vacuum Systen, Support Structure, Cooling System, and Assembly Equipment.

2. Contract WBS (CWBS)

The CWBS is the complete WBS for a specific contract developed by the contractor in accordance with this guide and the contract statement of work. It includes the PSWBS elements for the products (real estate, hardware, software, data, or service) which are to be furnished by the contractor. The contractor extend's these elements and defines the lower level products. The contract reporting requirements will indicate the CWBS levels or elements for which contract status is to be reported to DOE. Normally, the contractor extends each branch of the CWBS to the level where manageably sized increments of work are defined. A CWBS provides a consistent and visible framework that facilitates uniform plànning, assignment of responsibilities, and reporting of status.

\section{DEFINITION OF TERMS}

Many of the following terms have been extracted from DOE and draft DOE orders as shown in parentheses following the definition. Where a revision has been made to simplify, clarify, or avoid contradiction of terms, an asterisk follows the Order number. 
1. AREA. A portion of a site. This term is applicable at larger sites that have been segmented into "areas" for facilities planning or other purposes as opposed to a "special area" which is offsite. Example: The "30Ø Area" at Argonne National Laboratory (ANL) which is a portion of the ANL site devoted to primary research and development. (Draft DOE $4300.1 B$ )

2. BUILDING. An improvement which is suitable for housing people, materials, and/or equipment, or which provides only partial protection from the weather, such as a shed. (Draft DOE 4300.1B)

3. DATA. Known facts or figures. Quantitative information resulting from measurement.

4. ELEMENT (WBS). An individual product specified in the WBS. Each element below the end product is an item of real estate, hardware, software, data, or service. Each element name is, thus, a noun. The total of all the elements within a WBS defines the entire system or end product being developed or produced.

5. EQUIPMENT. The systems and devices used throughout DOE, and commonly referred to as equipment, are divided into three categories. (DOE $\left.4330.4^{*}\right)$

(a) Building Equipment. This category includes the mechanical and electrical systems that are installed as part of basic building construction and are essential to the normal functioning of the building space. Examples are a plumbing system or lighting system.

(b) Programmatic Equipment. This is equipment that serves a purely programmatic purpose; e.g., manufacturing, reactors or accelerator machinery, or chemical processing lines, and items of a similar nature.

(c) Other. This category includes all other equipment not covered in subparagraphs (a) and (b) above.

6. FACILITY. A general term used to describe any or all types of fixed site improvements, including buildings, structures, and utilities. (Draft DOE 4300.1B)

7. HARDWARE. Programmatic and other equipment and related parts. May be all or part of a system. See Equipment.

8. IMPROVED LAND. Land which has been cleared and graded, with common facilities provided; e.g., drainage, roads, walks, fences, guard towers, railroad. (DOE/MA-ø063, Cost Guide, Volume 6*)

9. PROJECT SUPPORT. A group of service products identifiable to a contract or projects including, for example, project management, and systems engineering. 
10. REAL ESTATE. Land and anything permanently attached such as buildings, fences, and those things attached to buildings, such as light fixtures, plumbing, and heating fixtures, or other such items which would be personal property if not attached. (Draft DOE $\left.4300.1 B^{*}\right)$.

11. REAL PROPERTY. Synonymous with Real Estate (Draft DOE $4300.1 B^{*}$ )

12. SERVICE. Product of professional aid not uniquely identifiable to a real estate, hardware, software, or data element.

13. SITE. Geographic entity comprising land, buildings, structures and utilities required to perform program objectives. Generally, all the required real property management functional organizations are represented at a site. That is, a site is not a satellite of some other site. (DOE $4330.4^{*}$ )

14. SOFTWARE. Programmed instructions to machinery or humans. Includes computer programs, operating procedures, instruction manuals, etc. May be all or part of a software system or an embedded element of a hardware system.

15. STRUCTURE. 1) A manner of organizing; e.g., work breakdown structure, organization structure, etc. 2) Any improvement that is not a building or a utility constructed on or in the land. Examples of structures include bridges, antenna towers, tanks, fixed cranes, roads, and sidewalks. (Draft DOE $4300.1 \mathrm{~B}$ )

16. SUBSYSTEM. Aggregation of component items (hardware and software) performing some distinguishable portion of the function of the total system of which it is a part. Normally, a subsystem could be considered a system in itself if it were not an integral part of the larger system. (Draft DOE 4700 of 8-28-85)

17. SYSTEM. A collection of interdependent equipment and procedures assembled and integrated to perform a well-defined purpose. It is an assembly of procedures, processes, methods, routines, or techniques united by some form of regulated interaction to form an organized whole. (Draft DOE 4700 of $8-28-85$ )

18. UNIFORM REPORTING SYSTEM. See Appendix A, Page 2, Paragraph 1.a.

19. UTILITY. A system, or any of its components, which stores, generates and/or distributes (via pipelines, wires, buses, or electromagnetic waves) a commodity or service to itself and/or to other facilities. (Draft DOE $4300.1 B^{\star}$ ) 
CHAPTER III

DEVELOPMENT AND MAINTENANCE OF A WBS

A. GENERAL

A prerequisite to the development of any WBS is the clear understanding and statement of the technical objectives and the end item(s) or end product(s) of the work to be performed. The project's functional design criteria and work scope developed during conceptual design provide the information to determine the project's objectives and subobjectives. The process of identification and definition of subobjectives assists in structuring the product elements during WBS development. Subobjectives derived from the overall project objective are allocated in such a way that identifiable subproducts support economically and technically viable subsets of the project objectives. In this manner, subsystems support a total system capability. This process may be repeated until the component level is reached.

In order to use the WBS as a framework for structuring the technical objectives of a project, in addition to its use as a management tool for cost and schedule control, it is important that the WBS be product oriented. Its elements should represent identifiable work products whether they be real estate, hardware, software, data or related service products.

Because of its product orientation a WBS provides one framework which can be used to plan, track, and assess the technical, schedule, and cost performance of the project. Because any WBS is a product structure, not an organization structure, complete definition of the WBS encompasses definition of work performed by all participants. The responsibilities for WBS activities are summarized in Figure 3. Numbers identifying responsibilities correspond with relevant paragraph numbers in paragraphs $B \& C$ below.

B. PROJECT OFFICE RESPONSIBILITIES

The DOE project office is responsible for developing and maintaining the PSWBS, and for negotiating and approving each CWBS.

\section{Prepare PSWBS}

The PSWBS should be developed early in the conceptual stages of the project and may be based initially on one used for another similar project. The PSWBS evolves during conceptual design from an iterative analysis of the project objective, the functional design criteria, the project scope, technical performance requirements, proposed methods of performance, including procurement, as well as drawings, process flow charts, and other technical documentation. See Appendix E for an example of development of a PSWBS. 


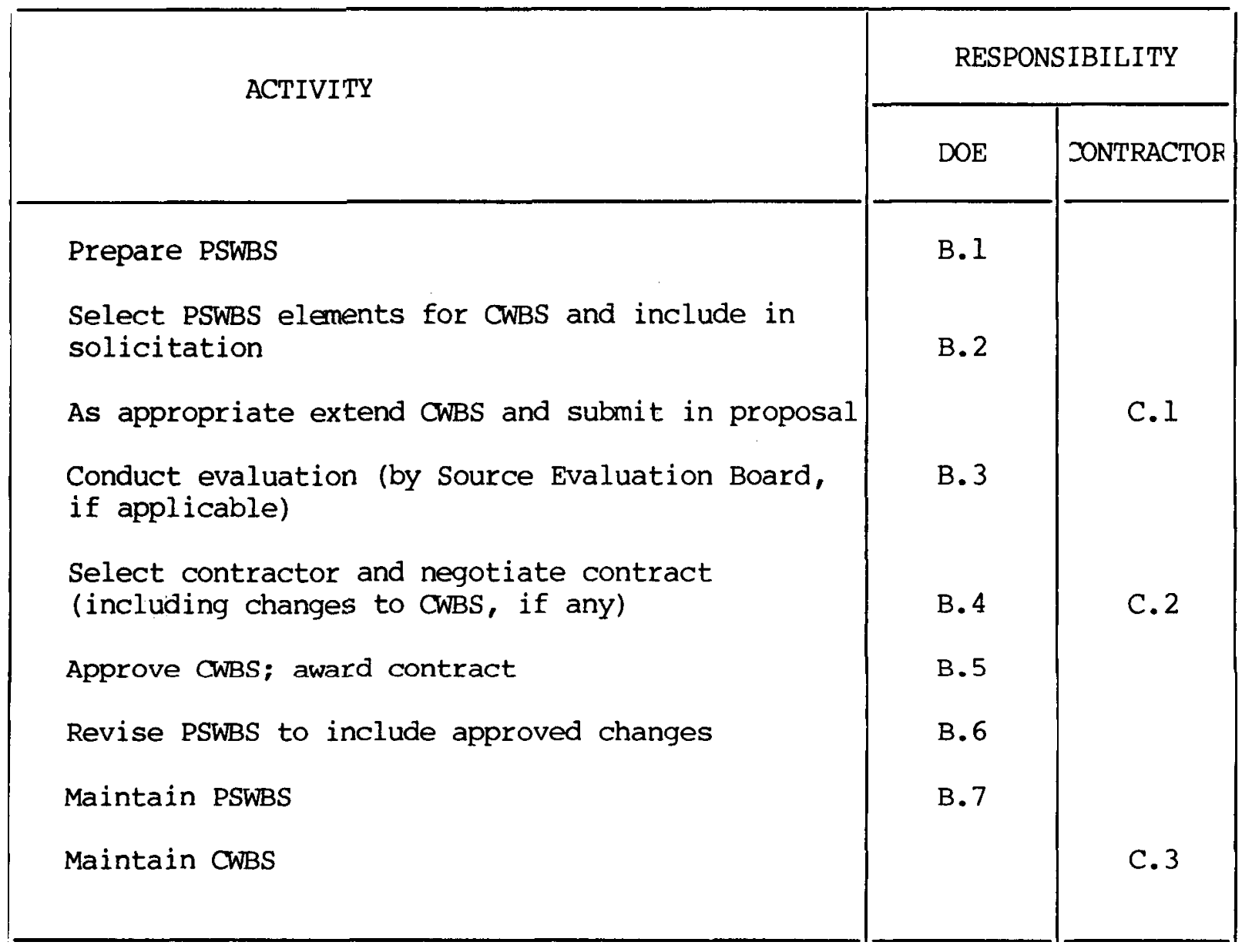

Figure 3. DOE and Contractor Responsibilities With Paragraph References

2. Select Elements for Solicitation

The DOE project office incorporates the PSWBS into each Request for Proposal (RFP) selecting the PSWBS elements for the work products that will be required by each contract. Each RFP includes the same PSWBS, which should include the initial WBS Dictionary, prepared by the DOE project manager using the formats shown in Appendix C. The RFP should instruct potential contractors to extend the selected PSWBS elements appropriately. (See Paragraph III.D.4).

3. Conduct Evaluation

The Source Evaluation Board or technical evaluation panel/contracting officer evaluates the CWBSs submitted by the proposers as part of the proposal evaluation process. (See Paragraph III.E.4.b.) 
4. Select Contractor; Negotiate Contract and CWBS Changes

DOE selects the winning contractor and negotiates the contract. The contractor may have proposed to DOE alternate approaches to better accomplish the contract objectives. If alternatives accepted and negotiated by the DOE project office impact the proposed CWBS, revisions to the CWBS will also be negotiated. (See Paragraph III.D.6)

5. Approve CWBS; Award Contract

Following DOE approval of the negotiated contract, including the CWBS, DOE awards the contract. The contract identifies the requirement for providing the WBS Dictionary by including DOE Form 1332.1, Reporting Requirements Checklist (see Appendix D), with the appropriate boxes checked.

6. Revise PSWBS As Required

Proposed changes to the PSWBS need to be carefully considered by the DOE project office prior to approving them. Since there is only one PSWBS for all participants, it may be preferable to constrain the affected branch(s) of the PSWBS to a higher level than originally intended. (See Paragraph III.D.6)

7. Maintain PSWBS

Final approval of the PSWBS is achieved through approval of the project plan. Once approved, the PSWBS should not be revised except at major transitional points in the acquisition process; e.g., from design to construction. (See Paragraph III.D.6)

\section{CONTRACTOR RESPONSIBILITIES}

1. Extend CWBS and Submit

The contractor extends the selected PSWBS elements appropriately to create a proposed CWBS to be submitted with the proposal. (See Paragraph III.D.4) If the solicitation requires a CWBS Dictionary, the proposal should use the forms in Appendix $C$.

Contractors may suggest changes to the selected PSWBS elements when a change is needed to meet an essential requirement of the RFP or to enhance the effectiveness of the CWBS in satisfying the project objective. In proposing a CWBS, a contractor may determine that the PSWBS contained in the RFP would force some unusual. requirements on his existing management control systems. The proposer may, therefore, suggest modifying the PSWBS to facilitate his approach to management.

\section{Negotiate Changes}

The proposed CWBS included in the successful proposal serves as the basis for negotiating an approved CWBS with DOE. (See Paragraph III.D.6) 


\section{Maintain CWBS}

The contractor maintains the CWBS including change traceability. Only DOE approved changes may be incorporated in accord with the contract terms. (See Paragraph III.D.6)

D. DEVELOPMENT CONSIDERATIONS

When project offices and prospective contractors develop the PSWBS and their CWBSs respectively, the following items below should be considered. Checklists to aid in this process are found in Paragraph III.E.4.

1. Compatibility of CWBSs with PSWBS

Each CWBS must contain the PSWBS elements selected by DOE, and must be structured and coded in such a way that technical, schedule and cost information may be readily summarized into the PSWBS. In turn, the PSWBS must accomodate the management needs of the winning contractors to the maximum extent practical.

2. Compatibility with Internal Organization Structure and Management Svstems

No WBS is an end in itself. It is a tool to be used by both DOE and contractor management. Management objectives and needs play a dominant role in the development of a WBS. Both DOE and contractor management have flexibility in developing a WBS to accomodate their objectives and needs, including their organization and management and reporting systems. Management plans to perform the work, produce the work products, and verify that they were correctly produced, and the manner in which contract support work efforts are organized, managed, and reported should be reflected in the WBS.

3. Correlation with other Reguirements (Project/Contract)

Each proposer's submittal should be based on the PSWBS contained in the RFP. However, particular attention should be given by both DOE and the proposing contractors to correlation of the CWBS with other requirements of the contract and the project.

4. Number of Levels (Project/Contract)

\section{a. PSWBS}

Normally, the PSWBS contains the top three levels only. Lower level elements may be included when necessary to clearly communicate all project requirements, or if there is a significant degree of technical risk associated with some lower level elements. The PSWBS may also end at level 2 for those elements where the DOE project office wishes to give the contractor flexibility to provide further definition. If detail levels are stipulated below the third level of a project the contractor's normal 
method of operation may be hampered, or excessive reporting requirements may result. These impacts may be discussed and minimized or alleviated through the negotiation.

The RFP should instruct contractors to extend the selected PSWBS elements to as low a level as necessary to provide a useful management tool.

b. CWBS

Work is performed by organization units, usually structured by function or type of work performed. This work is performed to satisfy technical objectives established for each product or subproduct identified as a WBS element.

Figure 4 illustrates typical organizational responsibility assignments for CWBS elements. In Figure 4, the Vice President is responsible for all construction work on all contracts for which the firm will do work. The General Superintendent is responsible for the construction work on this one CWBS, and the three supervisors shown are responsible for managing the performance of certain functions on all WBS elements requiring performance of these functions. On the branch of the CWBS shown here, the functional responsibility is shown at level five. Of course, the same supervisors might have responsibility for other work on other levels of the same and other branches.

As greater breadth or depth is achieved within a CWBS, each element's technical complexity and resource requirement is reduced. The number of levels and elements in the structure is generally dependent upon the size and complexity of the total effort, the degree of technical uncertainty, organizational structures concerned, and individual contractor management's judgment of need.

\section{c. Cost Account Level}

As the end product is subdivided into smaller and smaller subproducts at lower and lower WBS levels, the work effort required by each element can be identified to functional organization units at a lower and lower organization level. At some level on each WBS branch, the contractor will assign management responsibility for technical, schedule, and dollar cost performance. At this juncture of WBS element and organization unit, cost accounts are usually established and performance is planned, measured, recorded and controlled. To do so, the technical requirements for the work and work product must be specified, the work scheduled, budgeted, and performed, and product attainment of specified technical requirements verified. The responsible manager is called a cost account manager. To provide the responsible (cost account) manager with the technical, schedule, and cost information needed to manage the organization's work on the WBS element 


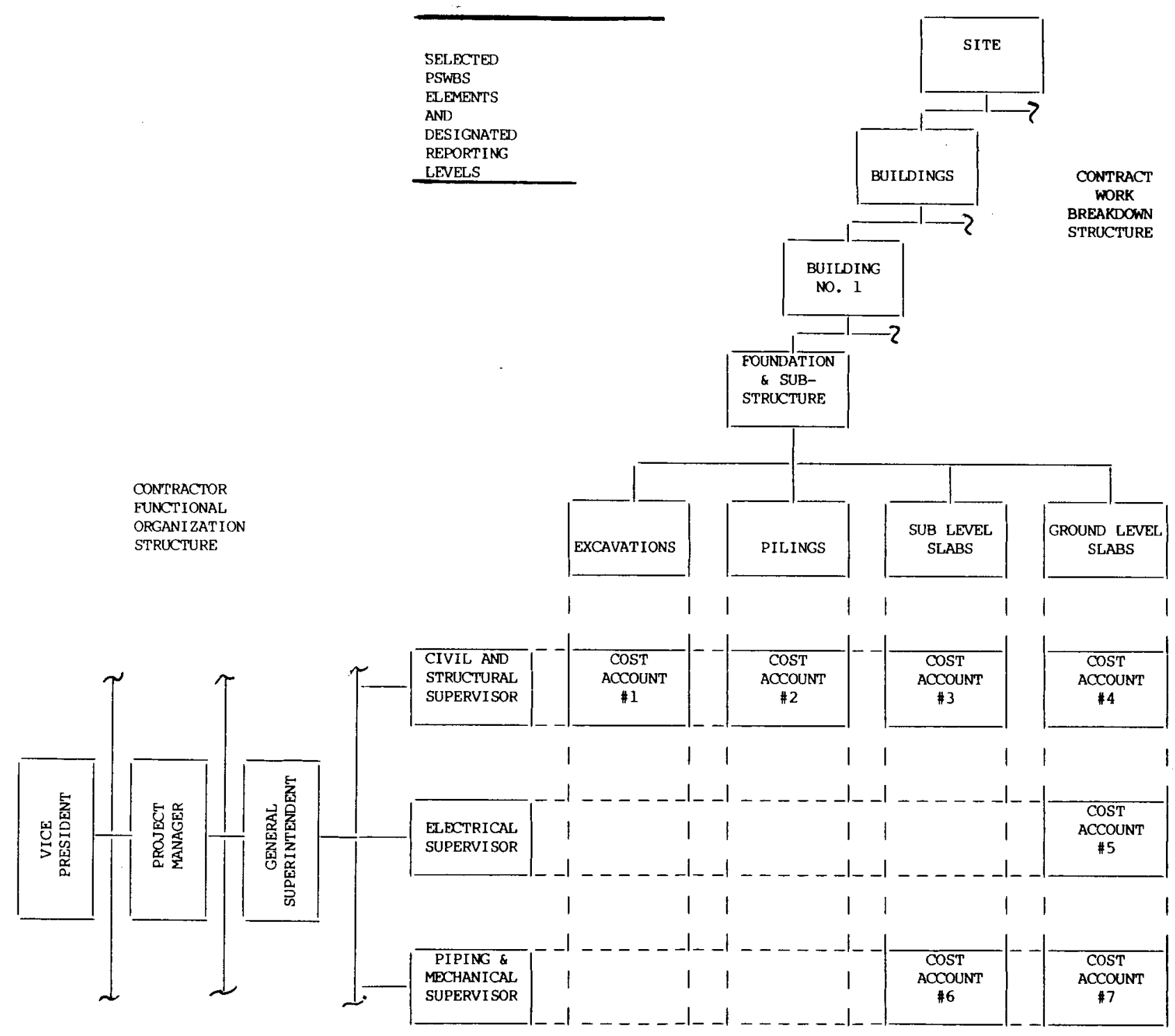

Figure 4. Integration of Contract WBS with Organization Structure 
for which he is responsible, all management control systems must be keyed to the same WBS element and organization unit for which he is responsible. The WBS level at which a cost account is established is primarily a function of the magnitude of the project and the type of product. The responsible organization level is a function of the management span of control and upper management's desire to delegate technical, schedule, and cost responsibility for product/WBS elements to lower management levels. In identifying cost accounts, the proposers must be allowed to establish organizational responsibilities at meaningful and appropriate levels. Otherwise, the proposers' existing management control systems and responsibility assignments may be impacted adversely.

Virtually all aspects of the contractor's management control systems, including technical definition, budgets, estimates, schedules, work assignments, accounting, progress assessment, problem identification, and corrective actions, come together at the cost account. Performance visibility is directly relatable to the level and content of the cost account. The DOE Cost and Schedule Control Systems Criteria Implementation Guide, DOE/MA0203, contains a detailed explanation of the cost account and related performance measurement concepts.

\section{All Inclusive (Products/Participants)}

a. PSWBS

Care should be taken to assure that the PSWBS represents a meaningful subdivision of technical objectives for all products and subproducts for all potential project participants, including designers, constructors, vendors, operators, and project managers. The PSWBS will be used to specify contract work products for all of the project participants.

b. CWBS

The WBS must similarly include, all work to be performed under the contract, specifically the WBS elements specified by DOE for reproting all products and services, at intermediate and lower levels, including contract line items, and major subcontracts as applicable. In some cases, the subcontracted effort may provide for delivery of a single lower level CWBS element, such as a vendor fabricated subassembly. In other cases, the subcontract may provide for effort covering several lower level CWBS elements, such as design for the electronics; communications, and instrumentation systems in a new facility. In either case, the prime contractor's CWBS dictionary (and other management control systems) must be capable of uniquely distinguishing major subcontractors' responsibilities from each other and from the work retained in-house by the prime contractor. This may be accomplished at the lower levels of the CWBS or at the cost account. 
Proposers may require the use of the WBS technique by subcontractors to permit fulfillment of CWBS requirements and to provide adequate control of the subcontract, and integration of subcontract reports with those of the prime contractor.

\section{Change Control (Within Phase/Between Phases)}

While strong efforts should be placed on early and accurate WBS planning, WBS revisions may result from expansion or contraction of project/contract scope, and the movement of a project through its various stages; for example, engineering, construction, and operation. Changes to the WBS should not be made after contracts are awarded and work is underway unless major rescoping of the project occurs. Users of this guide should understand that the sequence shown in preceding paragraphs may be iterative as the project evolves, contracts are awarded, and the work effort progresses through major project phases. Whenever the WBS is revised, the ability to crosswalk a track back to the previous WBS must be maintained.

\section{a. PSWBS (DOE Development)}

The WBS development process may be iterative. Changes may occur as the products of the work effort are more accurately defined or when a revised product structure resulting from technically different requirements or a more cost effective approach to satisfy the requirements should be used. The PSWBS should be revised to reflect changes resulting from contract negotiations.

The deliverable products of different project phases may differ; e.g., the products of the engineering phase may be sets of drawings, specifications and material lists, while the end products of the construction phase may be real estate, hardware, software, and data. However, the PSWBS for each phase should reflect the end products to be produced or constructed. That is, at PSWBS levels, the products of the engineering phase should be structured the same as the construction phase. Specifications, drawings, and lists should be treated as contractor work package deliverables, not as WBS elements.

\section{b. PSWBS (Contractor Proposed Change)}

Care must be taken in approving contractor proposed changes to the PSWBS so as to always maintain the ability to identify the interrelationships of each contractor's efforts to the overall technical objectives of the project. For example, in planning a project for construction of a nuclear generating plant, a PSWBS might be developed identifying such level 3 elements as Reactor Systems, Heat Removal System, Instrumentation and Control Systems, etc. A construction contractor may propose to hire a single subcontractor to do all the piping fabrication and installation for both the Reactor and Heat Removal elements. He might, therefore, recommend adding a PSWBS element at level 3 for 


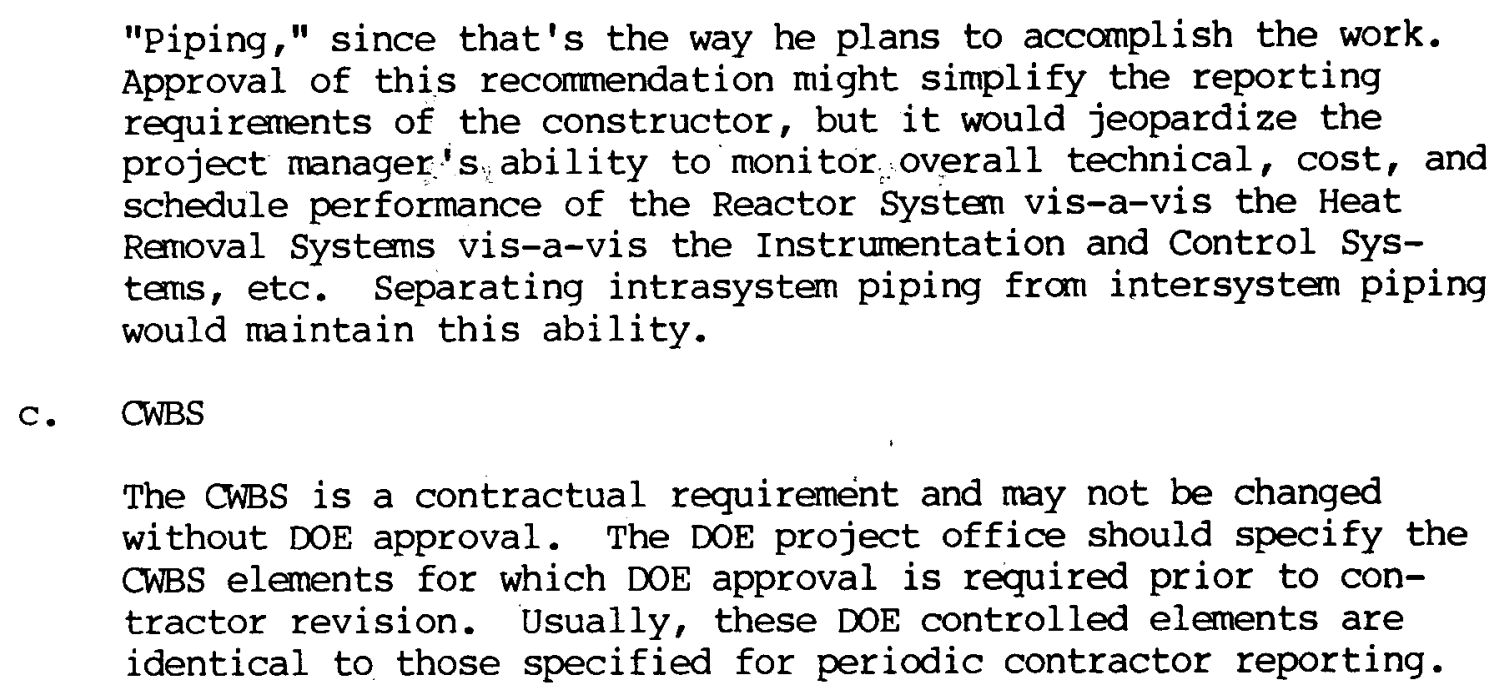

E. TECHNIQUES FOR WBS DEVELOPMENT

Techniques, which aid in development and use of a WBS, include coding of elements, preparation of graphic diagrams and a WBS Dictionary, and use of a development checklist.

1. $\quad$ Coding

Each WBS element is assigned a WBS element code to be used for its identification throughout the life of the project. A simple decimal or alphanumeric coding system is applied that logically indicates the level of an element and related lower level subordinate elements to the next higher level element. A common coding system facilitates communications among all project participants. Figure 2 illustrates a typical coding system that is easily traceable from level 1 to level 6. Each CWBS coding system must be traceable to the PSWBS coding system.

In addition to the requirements for sumarizing the technical, schedule and cost data through each CWBS and the PSWBS, there are many other legitimate requirements for nonproduct data summarizations. These other summarization requirements; e.g., code of accounts, organization structure, budgeting and reporting structure, can be accommodated through appropiate coding techniques. These categories may be accomodated through auxillary coding but should not, however, be forced into the WBS element code simply because they represent a legitimate need to structure data. "Paragraph' A.5 in Attachment A discusses in more detail the way in which the WBS coding structure can be related to other data structures supporting other project functions.

2. Diagrams

Diagrams of the WBS are routinely developed to provide a visual display. A pictorial view of the WBS visually aids the reader in 
understanding how lower level components of the project support and contribute to higher level components. The diagram is of the form often referred to as a "family tree" or "goes into tree" diagram. At level 2, WBS elements are conventionally shown with real estate, hardware, software, data and service elements from left to right.

\section{Dictionary}

The WBS Dictionary lists and defines the WBS elements. Initially prepared for the PSWBS by the DOE project manager, it is expanded in greater detail at lower levels by contractors as they develop their CWBSs. The dictionary consists of two parts. Part I is an index which lists WBS elements in indented format to show their hierarchical relationship to each other. Part II briefly describes each WBS element and the resources and the processes required to produce it, and provides a link to the detailed technical definition documents. Each element definition in Part II includes the:

a. System design description number - a coded link to quantitative technical engineering definition of process performance and product completion (Iten 10).

b. Cost content - resource identification (Item 12a).

c. Technical content - brief quantitative description of form, interface, and function (Item 12b).

d. Work statement - process identification (Item 12c).

The WBS Dictionary should be revised to reflect changes and should be maintained in a current status throughout the life of the project.

Appendix C contains an example WBS Dictionary, Parts I and II (Forms DOE-1332.10 and 1332.11, respectively) with instructions for preparation. Further guidance on the use of these forms is contained in DOE Order 1332.1A, UNIFORM REPORTING SYSTEM.

4. Checklists

Checklists are a useful tool for ensuring proper WBS developmient. Three separate checklists are provided, one for PSWBS development, one for CWBS development, and one for contractor proposed changes to the PSWBS. Though there is some similarity the focus of each is different.

\section{a. PSWBS}

The following checklist has been found useful in developing a PSWBS and to determine if all factors have been considered during development: 
(1) Has the PSWBS subdivided the end product into discrete and logical product oriented elements? Usually a project

subdivides into one or more real estate, hardware, software, data, and service product elements at level 2 .

(2) If there are any elements below level 3, are they of exceptional risk?

(3) Are the proposed PSWBS and the contemplated efforts complete, compatible, and continuous?

(4) Does the PSWBS provide for further logical subdivision of all project products requiring the application of resources?

(5) Do the PSWBS elements correlate with:

(a) The project specification tree;

(b) DOE system engineering requirements;

(c) Functional design criteria;

(d) Technical scope of work;

(e) Manufacturing, engineering and construction engineering requirements;

(f) Configuration management requirements; and

(g) DOE internal reporting level elements?

b. Contractor Proposed Changes to PSWBS

In approving contractor proposed changes to the PSWBS, the key issues to consider are:

(1) Can the revised PSWBS still provide a meaningful structure for relating the technical objectives of the various systems and subsystems to each other and to the total project?

(2) Does the revised PSWBS still define the deliverables and products which the DOE is buying?

(3) Does the revised PSWBS still provide a meaningful structure for measuring and controlling the technical, schedule and cost performance for the deliverables being procured?

(4) What is the impact on the contractor's management capabilities of disapproving the proposed PSWBS change?

(5) What is the impact on other contractors' CWBSs from accepting the proposed revision to the PSWBS? 
c. CWBSS

Normally, evaluation of the proposed CWBS should include the following items.

(1) Assure that the CWBS code structure is compatible with the PSWBS and that summarization of data into the PSWBS (by automated or other techniques) is possible.

(2) Assure that the proposed CWBS is compatible with the contractor's organization and management system, and the only one employed on the contract.

(3) Assure that CWBS elements correlate with the contract:
(a) specification tree
(b) line items
(c) end items
(d) data iterus
(e) work statement tasks
(f) configuration management requirements
(g) reporting levels.

(4) Assure that the contractor has defined distinct and logical product oriented CWBS elements down to the level where such definitions are meaningful and necessary for management purposes.

(5) Assure that CWBS elements encompass all the products of all the work contracted for with DOE.

(6) Assure that the CWBS elements encompass all the products of all the work to be performed under subcontract.

(7) Assure that level of effort work is minimized by eliminating high level functional WBS elements; e.g. design engineering is a function which should be planned, budgeted and costed in work packages assigned to unique product elements.

(8) Have modifications or changes involving new product elements been appropriately integrated?

\section{F. DEVELOPMENT CAVEATS}

Use of an unsuitable WBS from a prior project and incorporation of nonproduct and functional elements are three major errors in development of a WBS.

\section{Prior WBS Basis}

If the WBS from a prior project will be used as a basis for development of a WBS for a new project or contract, care should be exercised 
to not perpetuate any mistakes or undesirable features of the earlier WBS. Responsible personnel should discuss the adequacy of previous WBSs with the managers of those projects.

\section{Nonproduct Elements}

Many "elements" of a project are not technical products. A test facility, for example, is clearly a product, as are concrete slabs, and installed piping. However, design, mechanical engineering, concrete, piping labor, and direct costs are not products. Design is an engineering function; mechanical engineering and pipefitting are resource disciplines; concrete is a material resource; and direct costs is an accounting classification. As such, none of these "elements" are appropriate as WBS elements. Project phases (e.g., construction) and type of funds (e.g., Plant and Capital Equipment) are similarly inappropriate elements of a WBS. Rework, retesting and refurbishing should be treated as work on the appropriate CWBS element, not as separate elements. Care should always be taken to ensure that the names of WBS elements clearly indicate their product nature, to avoid semantic confusion.

\section{Functional Elements}

There is a natural tendency for contractors and individual managers to ask, "Where am I in that WBS?" They feel more comfortable if they see specific elements which reflect their functional areas of responsibility. When DOE project management is functionally organized in terms of design, construction, and operation, there may also be a tendency for the Government managers to approve these functionally oriented PSWBSs, since they also answer the question, "Where am I in the WBS?" However, both contractor and DOE managers are "in" the organization structure, not the WBS. The WBS should always retain its product orientation. It is not normally necessary for the WBS and organization structure to intersect at any but the top and cost account levels. This does not mean that all contractor proposed changes to the PSWBS should be categorically disapproved. Changes which enhance the contractor's ability to effectively manage the work, while retaining the DOE project office's ability to measure the technical, schedule and cost performance of the systems and subsystems being procured, should be allowed. 


\section{CHAPTER IV}

USE OF THE WORK BREAKDOWN STRUCTURE

A. GENERAL

The WBS is, first and foremost, a tool for project management. It provides a framework for specifying the technical objectives of the project by first defining the project in terms of hierarchically related product oriented elements and the work processes required for their completion. Coordinated use of the WBS for schedule, and budget/cost control on the project integrates these three primary aspects of project management. Figure 5 illustrates the concept. Each element of the WBS provides logical summary points for assessing technical accomplishments, and for measuring the cost and schedule performance accomplished in attaining the specified technical objectives.

For each WBS element, the detailed technical objectives are defined as well as the specific work tasks assigned to each contractor organization element and the resources, materials, and processes required to attain the objectives. The work tasks can be interrelated in networks representing their sequence, interdependency, and duration. Cost can then be added to the logic by assigning resource cost estimates to each scheduled task. As resources are employed and work progresses on the task, current technical, schedule, budget, and cost status, and estimate at completion data are reported. The task data then may be summarized to provide successive levels of management with the appropriate report on planned, actual, and predicted status of the elements for which they are responsible. Management will, thus, be better able to maintain visibility of status and to apply their efforts to assure desired performance.

\section{B. TECHNICAL MANAGEMENT}

The WBS provides a framework for defining the technical objectives, establishing a specification tree, defining configuration items, providing for Integrated Logistic Support (ILS), and for preparing and executing a Test and Evaluation Plan for a project.

\section{Specification. Tree}

A specification tree developed by system engineering structures the performance parameters for the system or systems being developed. It subdivides the system(s) into its functional constituent elements and identifies the performance objectives of the system(s) and its elements. The performance characteristics are explicitly identified and quantified. Completed, the specification tree represents a hierarchy of performance requirements for each constituent element of the system for which design responsibility is assigned. Because specifications may not be written for each product on the WBS, the specification tree may not map the WBS completely. Administrative tasks associated with system engineering and development of the specification tree are normally treated as a support services WBS element. 
DEFINE: 'THE PRODUCT

ANI) REI,ATED WORK

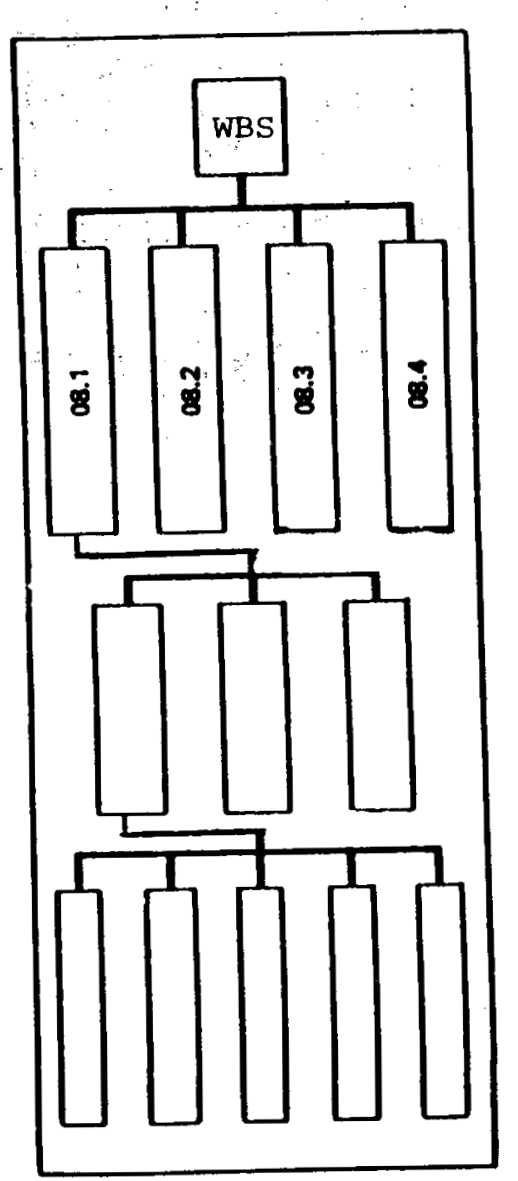

PLAN THE

WORK

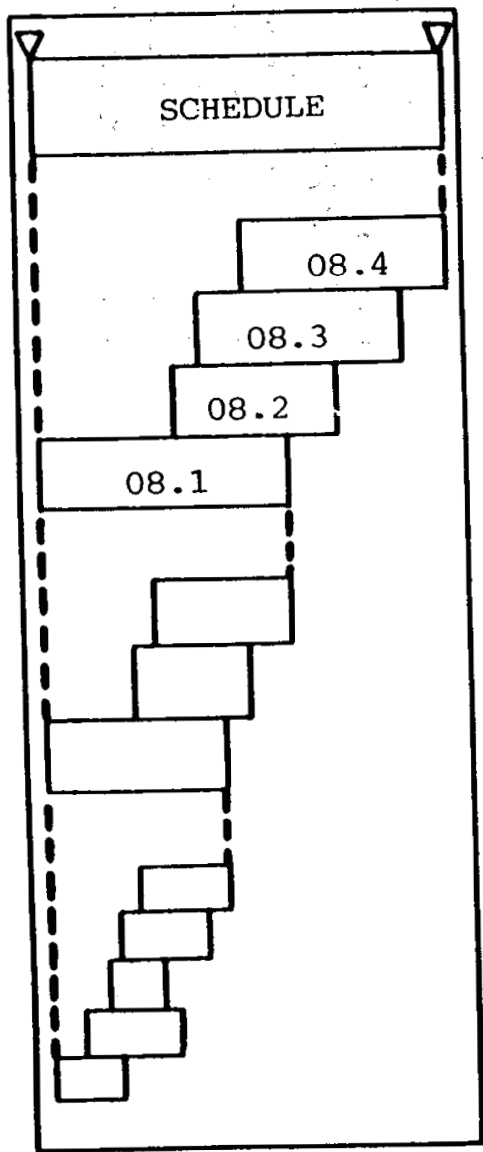

ALLOCATE THE

RESOURCES

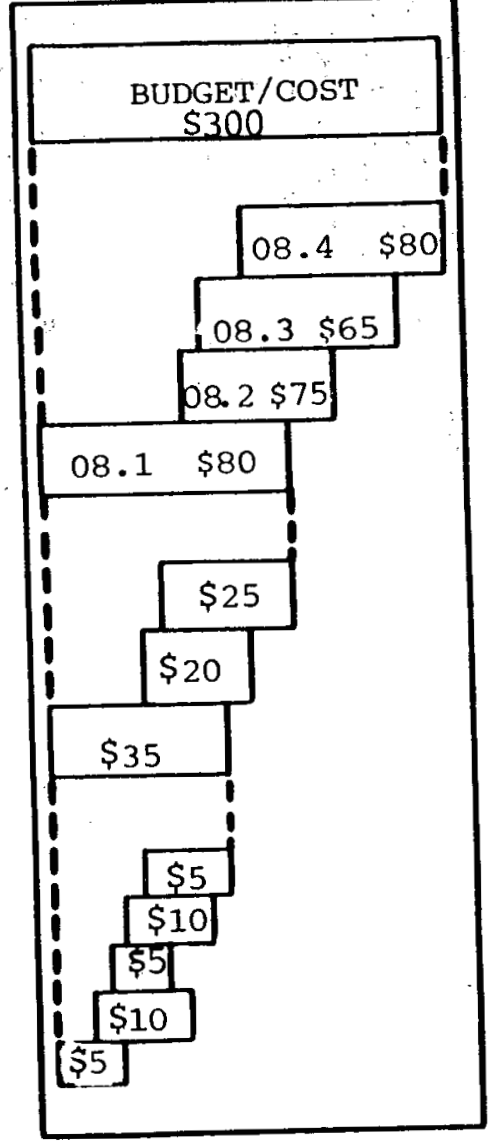

Figure 5. Technical - Schedule - Cost Integration 


\section{Configuration Management}

Configuration management is the process of managing the technical configuration of items being developed. In establishing the requirement for configuration management on a project, the DOE project office needs to designate which contract deliverables are subject to configuration management controls. A contract deliverable designated for configuration management is called a "Configuration Item." Configuration management involves defining the baseline configuration for the configuration items, controlling the changes to that baseline, and accounting for all approved changes. The framework for designating the configuration items on a project is the WBS, which needs to be extended sufficiently to clearly define all elements subject to configuration management. Configuration management tasks are normally associated with a support services WBS element.

3. Integrated Logistic Support (ILS)

ILS is all support necessary to assure the effective and economical support of a project, system, or equipment for its life cycle. These support efforts involve spare and repair parts inventories, warehousing, and control; preventive and scheduled facilities and equipment maintenance; reliability and maintainability data; transportation and handling systems; test equipment, training, and related publications. These support efforts require detailed definitions of the systems or components being supported, down to the individual spare part, or individual component receiving preventive maintenance. The WBS provides a hierarchical basis for such detailed definition. ILS tasks are usually associated with a support services WBS element. For example, planning and analysis tasks may be performed under systems engineering.

4. Test and Evaluation

Many projects require a formal Test and Evaluation Plan to ensure the procured systems satisfy the technical objectives of the project as defined by the project technical baselines. Test plans may be developed for individual elements of the WBS, and the effort associated with conducting and evaluating those tests may become part of the work defined for the appropriate WBS element. However, since tests may involve entire systems, parts of systems or individual components, they may not be uniquely identifiable to a single wBS element, but may span two or more of the elements going into one higher level WBS element. Such integration test work may be planned in conjunction with other work on the higher level element that incorporates the elements being tested. Alternatively, a second level "Test and Evaluation" element may be established for planning and controlling all tests.

\section{WORK IDENTIFICATION AND ASSIGNMENT}

People performing work are organized to facilitate effective management. Whether the organization is designed along project, function, or matrix 
lines, the organization structure reflects the way the people who will accomplish the work have been organized. To assign specific work responsibility to organization elements, the WBS and organizational structure should be integrated with each other; that is, functional responsibility is established for managing organization units performing specified work to produce defined products. This integration can occur at any level of the WBS but certainly occurs at the total project level and the level at which responsibility has been assigned to manage work. Other natural points of integration may occur as a result of the manner in which the scheduling, budgeting, work authorization, estimating and cost management systems interface with each other, with the WBS and with the organization. Figure 4 depicts integration between the WBS and the contractor's organizational structure.

\section{SCHEDULE MANAGEMENT}

Most projects of significant size have an integrated set of schedules from a master project schedule to successively more detailed intermediate level schedules to detail schedules for specified work to be performed.

\section{Plans}

The WBS provides a framework for detailed work schedule information based on technically verifiable product completion. A network of events (start, complete) and activities; e.g., design, construct, and install; must take place. There is a logic to the precedence relationships of the activities needed to produce and complete the WBS products. Resources; e.g., labor skill, dollars, and materials; and responsible organizations; e.g., mechanical engineering department, fabrication department, and subcontractor; can then be identified to each of the networked activities. This permits takeoff of a variety of activity and event schedules, each with a particular focus, but collectively integrated by virtue of the commonality of events. Designation of selected events as milestone events permits takeoff of "higher level" schedules suitable for "higher level" management. The number and type of schedules should be dictated by the scope and complexity of the work and the needs of management for schedule visibility. Notice that schedule levels and management levels need not coincide with WBS levels. There is no requirement for separate schedules for each WBS level.

Scheduling methodologies may vary. It is, however, important that scheduled events require completion of a tangible product in accordance with predefined specifications, and that such completion may be verified by test or inspection by persons other than those responsible for performance of the activities leading to completion of the product. Functional and project management can, thus, be assured that schedule performance is as reported, regardless of the level of detail included. 
2. Revisions

When work is underway, the impact of schedule changes may be readily assessed if a network is used because each WBS element's completion date is integrated with the schedule for completion of other elements, and the schedule for all supporting activities. That is, all elements going into a higher level element must be completed before the higher level element can be completed, and in some cases, before work on the higher level element can be started. This integration aids DOE project office review and approval of contractor proposed schedule changes.

\section{Status}

Product oriented schedules allow the project office to monitor the schedule baseline for the technical products of the project to ensure that the project objectives are completed on time. Periodic Uniform Reporting System (URS) Milestone Schedule Status Reports can be required of contractors to provide schedule status information in termis of duration. The cost Performance Report can be required to assess schedule performance in terms of earned value. The URS Status Report can be required to provide a narrative discussion. The DOE project office can use all of these reports to monitor schedule progress and to manage the project.

\section{E. COST MANAGEMENT}

The WBS technique assists management in measuring technical and schedule performance. Of equal importance is cost management. By breaking the total product into successively smaller entities, management can ensure that all required products are identified in terms of technical performance goals. Furthermore, management can verify that all work identified to the WBS, and hence charged to the effort, actually contributes to the project objectives. The planning of work by WBS elements serves as the basis for estimating and scheduling resource requirements. Subsequently, the assignment of performance budgets to scheduled segments of contract work identified to responsible organization units produces a time phased plan against which actual performance can be compared and appropriate corrective action taken when performance deviates from plan. This integrated approach to work planning also simplifies the identification of potential cost and schedule impacts of proposed technical changes.

1. Cost Estimating

Use of the WBS technique for cost estimating facilitates project and contract management. The technique provides a systematic approach to cost estimating that helps ensure that relevant costs are not omitted. An estimate derived by WBS element helps the DOE project office to plan, coordinate, and control the various project activities that DOE and the contractors are conducting. The WBS also provides a common framework for tracking the evolution of estimates; e.g. conceptual estimates, preliminary design estimates, and detailed design estimates. The technique can also provide a framework for life-cycle cost analysis. 
As periodic project cost estimates are developed, each succeeding estimate is made in an attempt to forecast more accurately the project's total cost. Basically, the estimates may be organized in two ways; by WBS element and by Code of Accounts (see Attachment A, Paragraph A.1). Both support the DOE project manager's on-going efforts in preparing budgets, evaluating contractor performance and updating the project's total cost. As projects move through the various phases of the acquisition process (conceptual design, preliminary design, detailed design, construction, testing, and operations) the estimate for the next phase in the cycle provides the basis for reassessment of the total project cost. This action also establishes the basis for contract negotiation with project participants. For example, the estimate for the construction phase to be used for invitation for bid packages is developed by the architect-engineer (A-E) upon completion of detailed design. The contractor, and other designated participants such as the operator, also prepare construction estimates based on detailed design. Each participant's estimate must be based on their own approved CWBS. All concerned parties must understand the structure, whether WBS or Code of Accounts, in developing the A-E estimate. Since each contractor CWBS may be different, any differences must be accomodated and reconciled to obtain valid, comparable estimates from the involved contractors.

2. Budgeting

In general, funds management involves periodic comparison of actual costs with time phased budgets, analysis of variances, and follow-up corrective action, as required. When WBS product elements and the supporting work are scheduled, a solid base for time phased budgets is ready made. Assignment of planned resource cost estimates to scheduled activities (tasks), and sumarization by WBS element by time period results in a time phased project/contract budget, which becomes the performance measurement baseline.

3. Accounting

a. Analysis and Control

If budgets are based on WBS elements, and time phased in accord with scheduled accomplishment, then the accounting process must similarly be able to cost WBS elements over time. That is, costed transactions must be coded in such a way that they can be identified to the WBS element which incurred the transaction cost, and to the time period when the transaction occurred. An accounting process or system which can accormodate the WBS approach has several advantages. The accounting system can be programmed to accept or reject charges to relatively small increments of work in accord with the planned time schedule for the work, thus minimizing unauthorized charges. Also, the accounting and financial organizations can better ensure that they have gotten what they paid for since products are accepted as complete 
only when a third party (inspector, quality control, next responsible manager, etc.) agrees that they meet the specified objectives. As a result, periodic accounting and financial variance analyses become more meaningful. Also, project performance measurement with its dependence on cost and schedule variance analysis becomes possible.

\section{b. Historical Data Base Development}

Cost information accounted for by WBS element can be used in estimating costs for pricing and negotiating contract changes and for follow-on procurements. Over time, DOE will accumulate a growing cost data bank of similar WBS elements from different projects. Such historical cost data can be used in conjunction with learning curve, regression and other techniques to estimate the cost requirements for like elements of new projects. Subsequent cost data collection by DOE can be compared to the original estimates to establish their validity, to identify trends, and to reestimate future project needs.

Contractors will similarly benefit from use of such data banks. They are expected to periodically provide a current estimate of future costs and the total estimated cost for each reporting element. Contractors are also expected to do a detailed bottoms up estimate periodically. The WBS provides the framework for summarizing detail costs. Since contractors tend to provide similar products on similar projects, the cost history accumulated can assist them in bidding future contracts and in budgeting new work.

\section{F. PERFORMANCE MEASUREMENT}

Proper use of the WBS technique accomplishes the Cost and Schedule Control Systems Criteria objectives of defining work and related resources, ensuring that all work is included, and that there is no duplication of effort.

In addition, the WBS is used to accumulate performance data elements and associated variances. This capability permits the contractor to evaluate progress in terms of contract performance. There is no need for separate contract performance assessments to be made at levels above the cost account since the WBS facilitates the summarization of data for successively higher levels of management.

The DOE Cost Performance Report Format 1 is designed to accomodate this information at a summary level, usually level 3 of the WBS. However, care must be exercised to ensure that correct summarization occurs so that all performance data is included and included only once.

Since performance data elements and variances can be progressively summarized by WBS, traceability of data is inherent in the contractor's management control systems. Although some variances may be washed out in the 
accumulation of both favorable and unfavorable variances during summarization, significant variances will usually appear at sumary WBS levels. It should be a relatively simple matter to trace these variances to their source through the WBS. 


\section{A. OTHER STRUCTURES}

DOE management control processes employ a variety of data accumulation structures other than the WBS, including the Uniform code of Accounts, the budget and reporting (B\&R) structure, and the cost element structure. Each structure presents a different view of data to facilitate control from the perspective of a range of program, project, financial, cost estimating, and other functional managers.

1. Uniform Cost Code of Accounts.

The DOE has a multi-level uniform code of accounts which is detailed at the first or primary and secondary levels in DOE/MA-ø063, VOLUME 6, COST GUIDE - COST ESTIMATING METHODS AND TECHNIQUES.

a. Purpose

According to the Cost Guide, the purpose of a code of accounts is to control and monitor costs and to provide a basis for financial and resources planning. However, in DOE it is used primarily to serve as a structure for early cost estimates. The code is then utilized for the duration of the project. Cost estimates essentially originate with engineering data assembled from items and categories most likely designated by systems or engineering technical disciplines. The cost estimate is compiled in this manner prior to the start of the project. The purpose is to define the scope of the dollar and resource commitment for the project. For the conceptual design cost estimate, the estimate will be prepared in accordance with the project cost code system, and all future estimates will be prepared on this same basis. When work starts on the project, cost data will be accumulated and reported in accordance with this system to provide consistency between estimates and actual cost data for cost control purposes.

b. Relationship of Primary Level Cost Codes to WBS Elements

An individual WBS element is a product of the application of resources which must be estimated and costed. In Figure $6, a$ process building plot plan is illustrated. Overlaid on the illustration are the related primary level cost codes. Since the building plan illustrates WBS elements, or products, it is clear that at the primary level the code of accounts maps the WBS to a significant degree. 


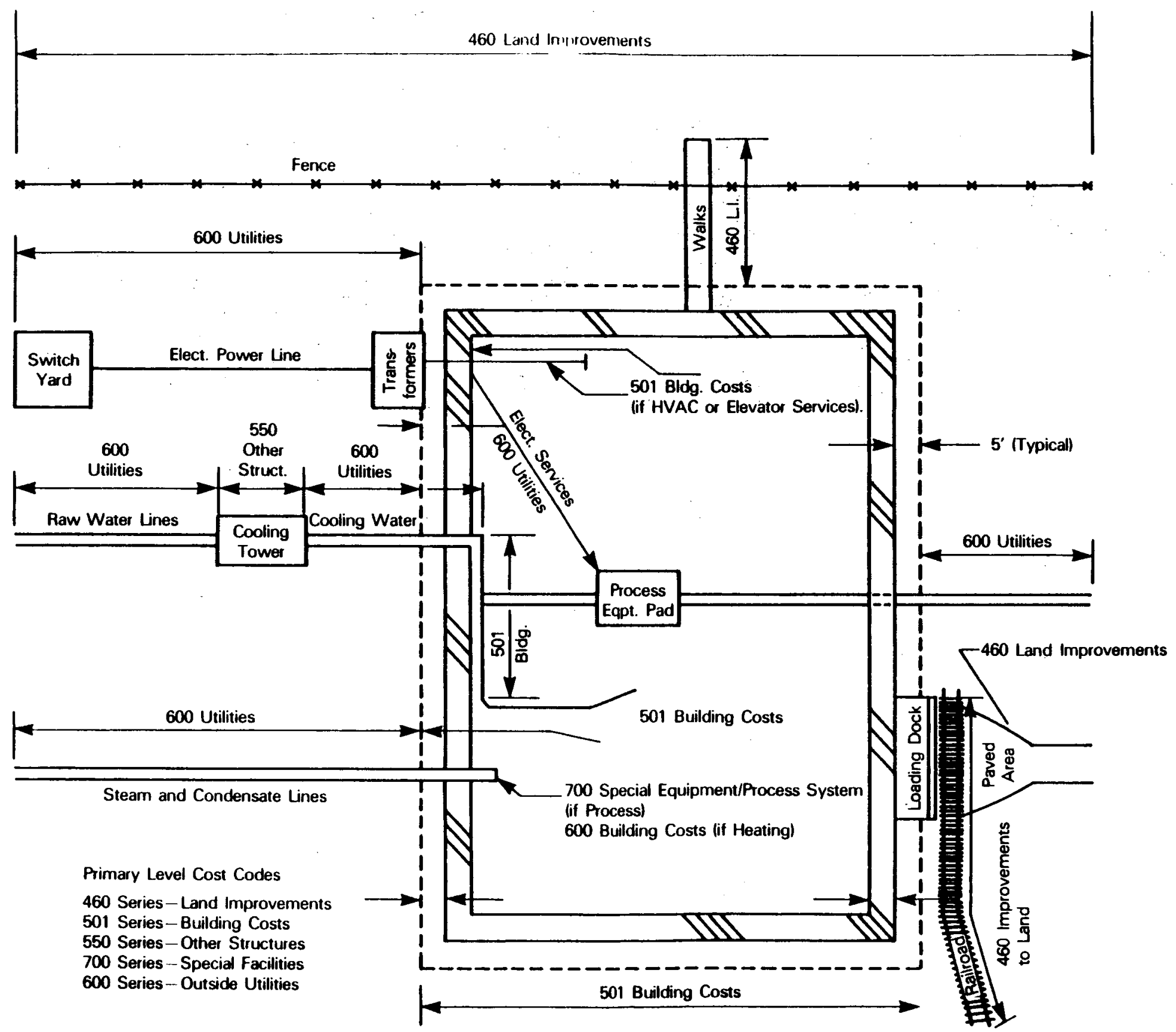

Figure 6. Plot Plan with Primary Level Cost Codes 
The Primary Level Cost codes are:

Level 1 Code

1) Land and Land Rights

2) Improvements to Land

3) Buildings

4) Other Structures

5) Utilities

6) Special Equipment/Process Systems

7) Improvements for Others

8) Demolition

9) Tunneling

10) Drilling

11) Standard Equipment
Asset Type Number

$\mathrm{N} / \mathrm{A}$

460

501

550

600

700

800

$81 \emptyset$

820

830

$\mathrm{N} / \mathrm{A}$

Note that 1 through 7 , and 11 are clearly products, while 8, 9, and 10 appear to be activities. In fact, "Tunneling" is defined as the code for the costs of a constructed tunnel, and "Drilling" is defined as the code for the cost of a completed well or hole. They are both product cost codes and would be WBS elements called "Tunnel(s)" and "Well(s)" or "Hole(s)," respectively. "Demolition" is similarly a code for costs associated with the activity which produced a cleared area where once there were "existing structures, equipment and materials." In WBS parlance, "Demolition" is work performed by resources applied to a WBS element. The WBS element would be either the Demolished structure, or the Cleared Area.

c. Relation of Secondary Level Codes to WBS Elements

Essentially the code of accounts crosscuts the WBS much as the organization structure does. The interface between the WBS and the project's cost codes is illustrated in Figure 7. This interface is similar to that shown for the Organization/WBS interface or matrix except that there are no "cost accounts" at the intersection and the code of accounts hierarchy is substituted for the organization hierarchy. Because of the interface between the code of accounts and the WBS, a cost estimate based on WBS elements can be summarized to higher levels along either line.

Figure 8 illustrates the project code of accounts structured in a detailed matrix for construction effort only... The row headings correspond to the primary and secondary level accounts of the direct construction cost codes. The column headings, designated "areas," correlate with high level WBS real estate elements or groups of high level real estate elements. These elements are not specified on the blank form because they must necessarily be different for each new project. Areas would normally correspond to level two or three of the PSWBS. In the example in Figure 8, the first three columns have been labeled to correspond with the 


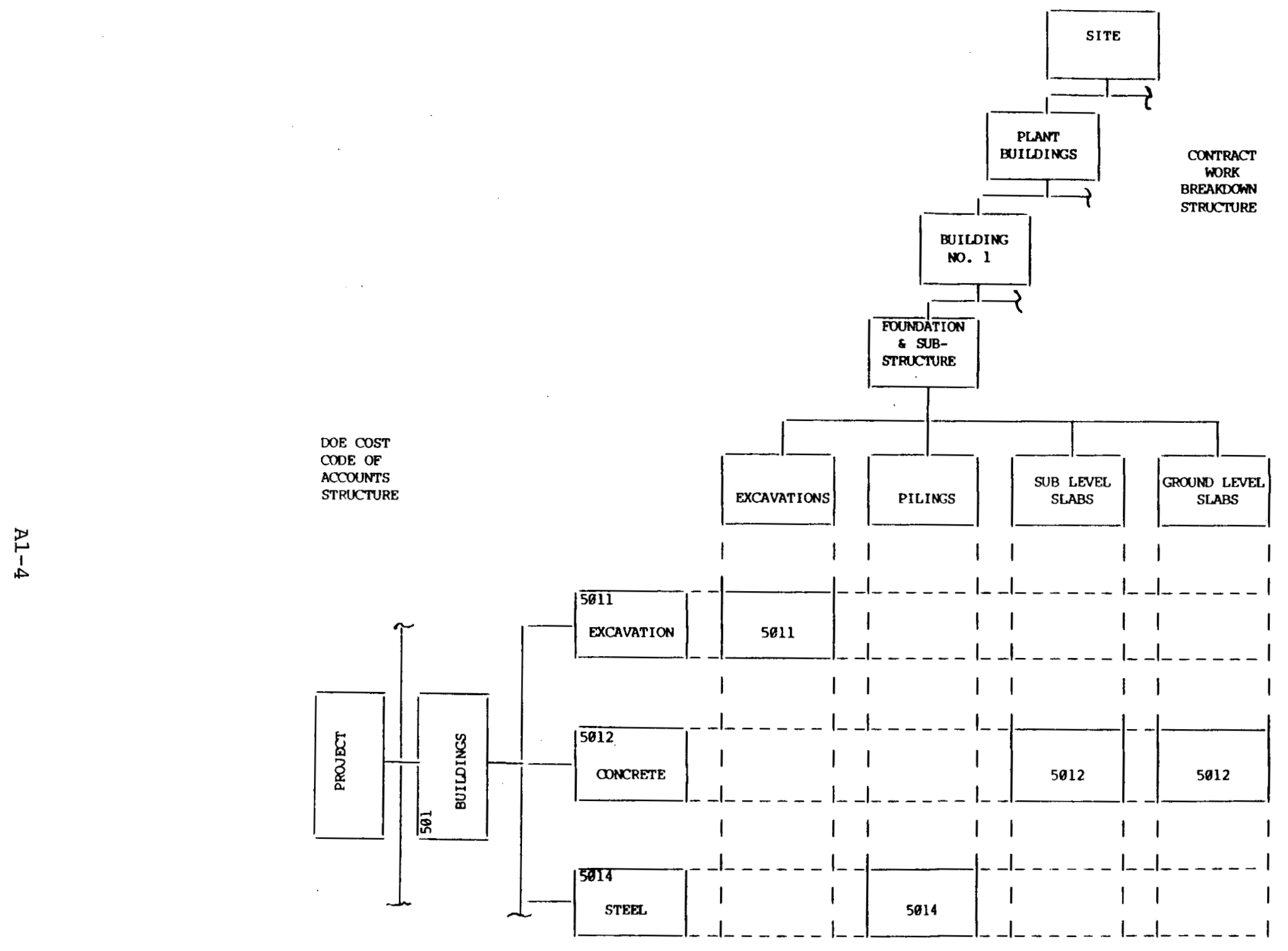

Figure 7. Integration of Contract WBS and Secondary Level Cost Codes 


\begin{tabular}{|c|c|c|c|c|c|c|c|c|c|}
\hline & CATEGORY & BLDG 1 & BLDG 2 & BLDG 3 & AREA 4 & AREA 5 & AREA 6 & AREA 7 & TOTAL \\
\hline \multirow[t]{10}{*}{460} & Improvements to Land & & & & & & & & \\
\hline & 4601 Site Preparation & & & & & & & & \\
\hline & 4602 Drainage & & & & & & & & \\
\hline & 4603 Land scaping & & & & & & & & \\
\hline & 4605 Railroads & & & & & & & & \\
\hline & 4606 Port Facillties & & & & & & & & \\
\hline & $\begin{array}{l}4700 \text { Roads, Walks \& Paved } \\
\text { Areas }\end{array}$ & & & & & & & & \\
\hline & 4800 Fences $\&$ Guard Towers & & & & & & & & \\
\hline & $\begin{array}{c}900 \text { Other Improvements to } \\
\text { Land }\end{array}$ & & & & & & & & \\
\hline & Subtotal & & & & 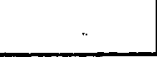 & & & & \\
\hline \multirow[t]{11}{*}{501} & Buildings & & & & & & & & \\
\hline & 5011 Excavation \& Backfil1 & 185.9 & & & & & & & 185.9 \\
\hline & $\overline{5012 \text { Concrete }}$ & 299.2 & 93.9 & 72.3 & & & & & 465.4 \\
\hline & 5013 Masonry & & & & & & & & \\
\hline & 501: Metals & & & & & & & & \\
\hline & 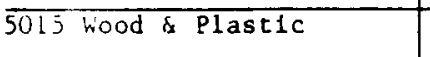 & & & & & & & & \\
\hline & 5016 Finishes & & & & & & & & \\
\hline & 5017 Special Construction & & & & & & & & \\
\hline & 5018 Mechanical & & & & & & & & \\
\hline & 5019 Electrical & & & & & & & & \\
\hline & Subtotal & & & & & & & & \\
\hline \multirow{11}{*}{550} & Other Structures & & & & & & & & \\
\hline & 5501 Excavation \& Backfil1 & & & & & & & & \\
\hline & 5502 Concrete & $\ldots$ & & & & & & & \\
\hline & 5503 Masonry & & $\cdots$ & $\therefore$ & & & & & \\
\hline & 5504 Metals & & & & & & & & \\
\hline & 5505 Wood \& Plastlc & & & & & & & & \\
\hline & $\begin{array}{l}5506 \text { Thermal \& Molsture } \\
\text { Protection }\end{array}$ & $\cdots$ & $\overline{7}$ & . & & ? & & & \\
\hline & 5507 Special Construction & & & ${ }^{*}$ & & & & & \\
\hline & 5508 Mechanical & & & & & & & & \\
\hline & 5509 Electrtcal & & & & & & & & \\
\hline & Subtotal & & & & & & & & \\
\hline
\end{tabular}

Figure 8. Project Cost codes for Construction (Matrix) 


\begin{tabular}{|c|c|c|c|c|c|c|c|c|c|}
\hline & CATEGORY & BLDG 1 & BLDG 2 & BLDG 3 & AREA 4 & AREA 5 & AREA 6 & AREA 7 & TOTAL \\
\hline \multirow[t]{12}{*}{600} & 0 Utilities & & & & & & & & \\
\hline & 6100 Communications Systems & & & & & & & & \\
\hline & $\begin{array}{c}6150 \text { Elec. Trans. \& Dlst. } \\
\text { Systems }\end{array}$ & & & & & & & & \\
\hline & 6210 A1arm Systems & & & & & & & & \\
\hline & $\begin{array}{c}6250 \text { Gas Trans. \& Dist. } \\
\text { Systems }\end{array}$ & & & & & & & & \\
\hline & 6300 Irrigation. Systems & & & & & & & & \\
\hline & 6400 Sewerage Systems & & & & & & & & \\
\hline & $\begin{array}{c}6450 \text { Steam Gen. \& Dist. } \\
\text { System }\end{array}$ & & & & & & & & \\
\hline & $\begin{array}{r}6500 \text { Water Supply, Pumping } \\
\text { Treat. \& Dist. Sys. }\end{array}$ & & & & & & & & \\
\hline & $\begin{array}{c}6600 \text { Oil Pipe \& Dist. } \\
\text { System }\end{array}$ & & & & & & & & \\
\hline & 6900 Other Utilities & & & & & & & & \\
\hline & Subtotal & & & & & & & & \\
\hline \multirow[t]{4}{*}{700} & Special Equipment/Process Sy & ystems & & & & & & & \\
\hline & 7010 Vessels & & & & & & & & \\
\hline & $\overline{7020}$ Heat Transfer & & & & & & & & \\
\hline & \multicolumn{9}{|l|}{7030 Mechanical Equipment } \\
\hline & $\overline{7040 \text { Package Units }}$ & & & & & & & & \\
\hline & 7050 Piping & 379.8 & & & & & & & 379.8 \\
\hline \multicolumn{10}{|c|}{7060 Electrical } \\
\hline \multicolumn{10}{|c|}{7065 Instrumentation } \\
\hline \multicolumn{10}{|c|}{7070 Protective Cover } \\
\hline \multicolumn{10}{|c|}{7080 Reactor Components } \\
\hline \multicolumn{10}{|c|}{ Subtotal } \\
\hline \multicolumn{10}{|c|}{800 Improvements for Others } \\
\hline \multicolumn{10}{|c|}{810 Demolition } \\
\hline \multicolumn{10}{|c|}{820 Tunneling } \\
\hline \multicolumn{10}{|c|}{830 Dr1l11ng } \\
\hline \multicolumn{10}{|c|}{$\star * *$ Total Direct Costs $\star \star \star$} \\
\hline \multicolumn{10}{|c|}{ 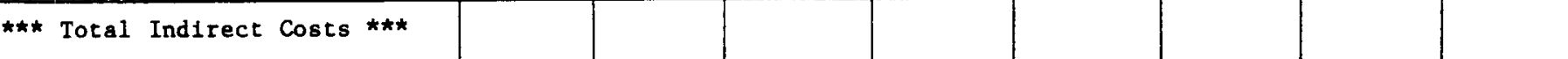 } \\
\hline & $\star \star \star \star \star \star \star$ Total $\star \star \star \star$ & & & & & & & & \\
\hline
\end{tabular}

Figure 8. Project Cost Codes for Construction (Matrix)

(Continued) 
buildings for which concrete has been estimated in Figure 9. The figures corresponding to those in Figure 9 (see Paragraph d. below) have been shown in the first three columns.

d. Sample cost Estimate for Concrete

Figure 9 shows a cost estimate for "concrete". Costs for products made with concrete have been estimated for all elements of the WBS. Estimating in this fashion allows the estimate to be summarized through higher levels of the WBS, thus assisting in technical, cost and schedule control of the different parts of the plant. The total estimate for the concrete cost code might be used to let a fixed price subcontract for concrete work spanning all of the WBS elements or to budget for and authorize a responsible concrete superintendent to do the concrete work in house. In this manner, a contractor would be able to monitor the performance of the concrete subcontractor or concrete superintendent incrementally by WBS elements.

\section{Budget and Reporting (B\&R) Structure}

The DOE has a multi-level B\&R structure which is detailed annually.

a. Purpose

It is DOE policy that a system of $B \& R$ accounts be maintained in accordance with generally accepted commercial and industrial accounting principles and practices, modified where necessary to meet particular DOE needs, to comply with the Budget and Accounting Procedures Act of 1950, and to fulfill the requirements of other Federal statutes and Government regulations. One of the key objectives of the DOE accounting system is to provide for the accumulation and classification of obligations and outlays for financial estimating and reporting. The $B \& R$ structure aids in meeting this objective. The Controller, with the help of Departmental Elements, develops current B\&R classifications and definitions covering the specific functions and activities for which they are responsible.

b. Relation to WBS

A WBS is used to structure work on a project. The B\&R is used to structure fiscal budgeting and reporting of programs which may consist of one or more projects or subsets of projects. The hierarchical B\&R Structure is shown below (A indicates alpha; N indicates numeric):

Code

$A A$

NN

NN
Terminology

Program

Subprogram

Category

Task

Subtask 


\begin{tabular}{|c|c|c|c|c|c|c|c|c|c|}
\hline \multirow{2}{*}{\multicolumn{2}{|c|}{ ITEM AND DESCRIPTION }} & \multirow[t]{2}{*}{ QUANTITY } & \multirow[t]{2}{*}{ UNIT } & \multicolumn{2}{|c|}{ MANHOURS } & \multicolumn{2}{|c|}{ UNIT COST } & \multicolumn{2}{|c|}{ TOTAL COST } \\
\hline & & & & $\begin{array}{l}\text { PER } \\
\text { MAT ' } L \\
\text { UNIT }\end{array}$ & TOTAL & MAT'L & LABOR & MATERIAL & LABOR \\
\hline & CONCRETE SUMMARY & & & & & & & & \\
\hline 5012 & $\begin{array}{l}\text { MAIN BLDG. NO. } 1 \text { SUBSTRUC- } \\
\text { TURE CONCRETE }\end{array}$ & 7,100 & $\mathrm{CY}$ & 4.4 & 31,450 & $\$ 45.84$ & $\$ 6.59$ & $\$ 325,500$ & $\$ 2 \varnothing 7,4 \varnothing 0$ \\
\hline 5012 & $\begin{array}{l}\text { MAIN BLDG. NO. } 1 \text { SUPER- } \\
\text { STRUCTURE CONCRETE }\end{array}$ & 870 & $\mathrm{CY}$ & 15.6 & 13,560 & 73.22 & 6.76 & $63,7 \varnothing \emptyset$ & 91,800 \\
\hline 5011 & TURBINE PEDESTAL CONCRETE & 2,700 & $\mathrm{CY}$ & 6.0 & 16,130 & 63.59 & 6.86 & 171,700 & 110,700 \\
\hline 5011 & MISC. EQUIPMENT FOUNDATIONS & 1,980 & $\mathrm{CY}$ & 5.9 & 11,750 & 45.71 & 6.40 & 90,500 & $75,20 \emptyset$ \\
\hline 7050 & CIRC. WATER SYSTEM CONC. & 9,400 & $\mathrm{CY}$ & 5.3 & 49,550 & $41.7 \varnothing$ & 7.66 & 392,100 & 379,800 \\
\hline 5012 & $\begin{array}{l}\text { MAJOR AUXILIARY BLDG. Nø. } 2 \\
\text { CONCRETE }\end{array}$ & 1,600 & $\mathrm{CY}$ & 9.2 & $14,69 \emptyset$ & $49 . \varnothing \varnothing$ & 6.32 & $78,40 \emptyset$ & 93,900 \\
\hline 5012 & $\begin{array}{l}\text { MISCELLANEOUS BLDG. NO. } 3 \\
\text { CONCRETE }\end{array}$ & 1,500 & $\mathrm{CY}$ & 7.4 & 11,680 & 48.33 & 6.52 & 72,500 & 72,360 \\
\hline CODE & & & & & & & & & \\
\hline CONCR & TOTAL CONCRETE & $25,15 \emptyset$ & $\mathrm{CY}$ & 5.89 & 148,210 & $\$ 47.50$ & $\$ 6.96$ & $\$ 1,194,40 \emptyset$ & $\$ 1,031,100$ \\
\hline
\end{tabular}

Figure 9. Project cost Estimate for Concrete 
Note that a project may be at any $B \& R$ level, and may be distributed to one or more lower levels. The relationship between $B \& R$ and WBS is thus variable. Because of this, a column is provided on the Form DOE F1332.10, WBS Dictionary Part I, in which the appropriate $B \& R$ codes may be entered to define the specific relationship for each WBS and its elements.

3. Cost Element Structure

DOE also employs a cost element structure.

a. Purpose

A uniform classification of cost element accounts assists in integration of industrial cost accounting and commercial accounting with Government fiscal and accounting procedures. This approach provides for the maintenance of one integrated set of general ledger accounts covering all funds, property, other assets, liabilities, expenses, and revenues. Figure 10 shows a typical structure to budget and collect expense information by cost element (type of resource). Accounting measures the acquisition of these resources over time, while cost estimating predicts what they will be, and scheduling and budgeting project the periods in which they will be obtained and the cost incurred.

b. Relationship of cost Element Structure to the WBS

As work is progressively detailed planned and budgeted it is budgeted by the type of resource used to produce the detailed WBS element (cost account). This will include at a minimum the direct cost elements of labor, material and oDCs. Indirect costs may or may not be allocated at the detail level. After work begins and costs are recorded this separate identification of cost elements will assist in determining the causes of cost variances at the detailed level for later accumulation and summarization along both cost element and WBS lines. Since material and equipment are products some or all would be expected to appear as elements on the WBS. Although some contract indirect costs are for products; e.g., hand soap; since they are not components of the end product they do not appear as WBS elements.

\section{Master Format Structure}

DOE also employs a master format, structure.

a. Purpose

The master format structure was promulgated by the Construction Specifications Institute (CSI) for preparation of contract documents (plans and specifications). The structure is being 
$1 \emptyset \emptyset$ DIRECT COSTS

101 Labor Engineering Direct

102 Labor Engineering Overtime

103 Labor Technician Direct

104 Labor Technician Overtime

105 Labor Drafting Direct

106 Labor Drafting Overtime

110 Materials

120 Subcontracts

130 Equipment

140 Other Direct Costs

141 Project Travel

142 Engineering Supplies

143 Graphic Support

$20 \emptyset$ INDIRECT COSTS

2Iø Overhead

211 Clerical and Administration

212 General Travel

213 Office Supplies

214 Books

215 Forms

216 Miscellaneous Supplies

220 General and Administrative

221 Office Furniture Rental

222 Equipment Maintenance

223 Taxes

224 Insurance

225 Professional Services

226 Professional Memberships

227 Other

230 Cost of Money

Figure 10. Project Accounting Cost Element Structure Example 
adopted for the General Design Criteria specified in DOE Order 6430.1. Figure 11 illustrates the division level codes and the subsidiary broad scope section codes for the concrete division.

b. Relationship to WBS

A large part of the general design criteria consists of regulations, codes, standards, guides and DOE directives which are inherently "general"; i.e., they apply to a wide range of similar construction project products and materials. In addition, construction contractors (except general contractors), the crafts they employ, and their materials and components suppliers; e.g., a masonry contractor, masons, and brick yards, tend to specialize in materials related lines of work. As a result the "Master Format" structure promulgated by the CSI for preparation of contract bid documents (plans and specifications), incorporates some product elements and some materials elements at the top "Division" level. Examples of product oriented divisions include, 8 - Doors and Windows, 10 - Specialties, and 11 - Equipment. Examples of division level elements which are material oriented include: 3 - Concrete, 4 - Masonry, 5 - Metals, and 6 - wood and Plastics. Because the CSI division level groupings are applied to project specific purchased, fabricated, and constructed products hierarchically related by the WBS, a cross reference mechanism is required to relate the two.

\section{5. $\quad$ Coding}

A WBS provides a basis for integrated management of related functions including work responsibility assignment, estimating, scheduling, budgeting, funding, accounting, and performance measurement. WBS identification can be used in each of these functions to form a common basis by which they can be related to technical project objectives, to specific work activity, and to each other. An extension of, or matrix to, the WBS coding allows the WBS to bind together these project management control functions while satisfying the WBS's main purpose of providing a framework for planning and accomplishing the technical objectives of the project.

The coding developed for the WBS and that developed for estimating, funding, accounting, etc., must relate to one another. An example of the coding that might be related to an individual time and or material transaction is illustrated below:

$\begin{array}{ll}\text { WBS } & 1.2 .1 .1 .1 \\ \text { CODE OF ACCOUNTS } & 5 \emptyset 1141 \\ \text { ORGANIZATION } & \emptyset \emptyset 6 \\ \text { COST ELEMENT } & 1 \emptyset 1 \\ \text { B\&R } & \text { AA NN NN NN N }\end{array}$




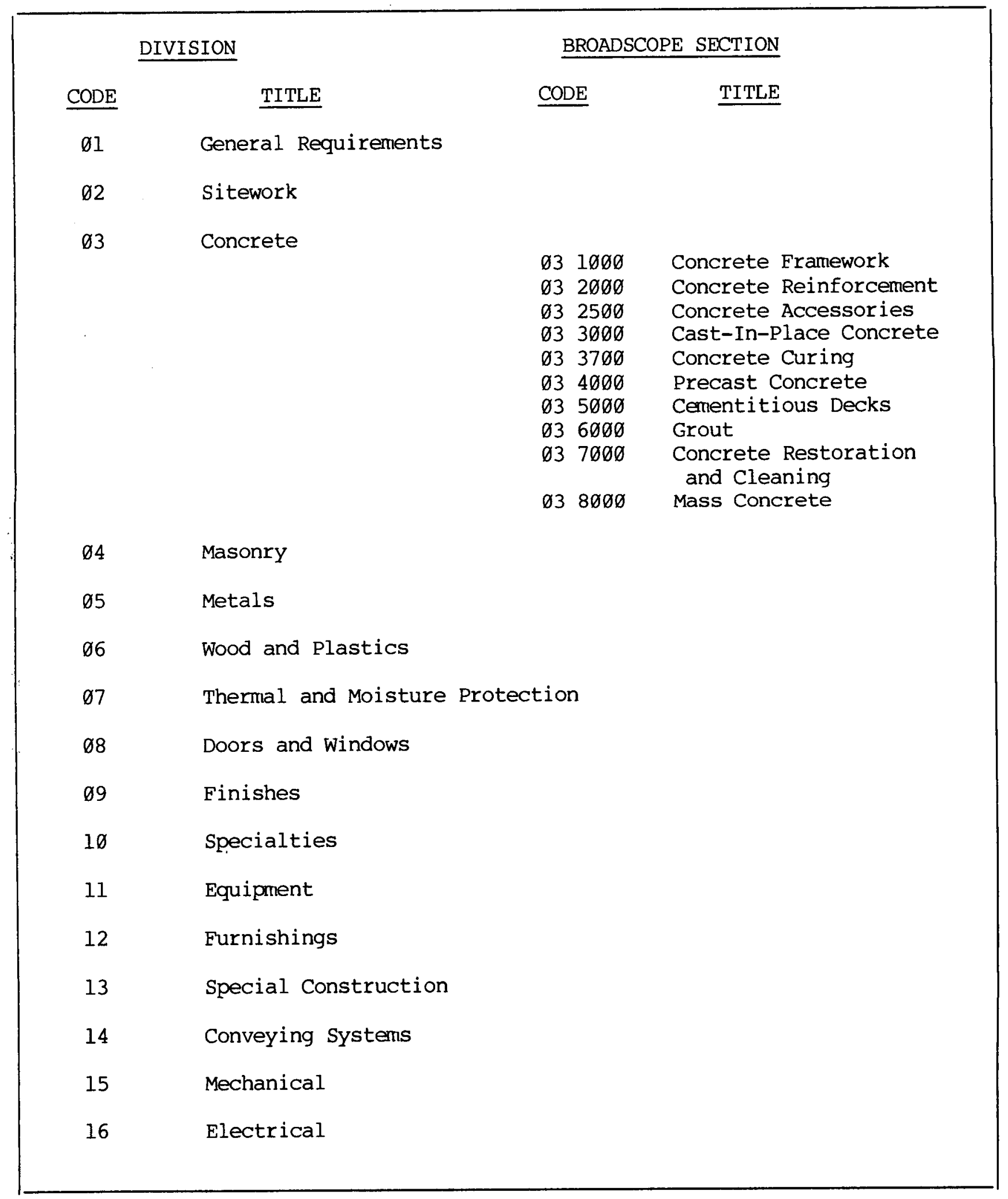

Figure 11. Excerpts from Construction Specifications Institute (CSI) 'Masterformat' 
The first code is the coding down to level 5 of the WBS. The second code is the third level of the DOE Code of Accounts for cost estimating and historical cost collection. The third code identifies the organization responsible for the work. The fourth code identifies the cost element. The fifth code labels the cost as part of a particular B\&R classification.

There is no need to carry each of these codes on every transaction or document. For example, since a time card must carry the worker identification, it need not carry the responsible organization code nor the cost element code since both may be looked up in a table or matrix (see Figure 12). Since it must carry the work package number, it need not carry the code for the WBS element on which the work will be performed nor the B\&R number. It should carry the applicable level 3 code from the code of accounts, since the level 3 code may span multiple WBS elements and the WBS element may span multiple level 3 codes. A similar logic applies to other charges. Additionally, more compact coding systems may be developed.

\section{B. DOE WIDE PROCESSES}

As shown by the following paragraphs, DOE policy stresses a product basis for conducting the relevant processes of cost estimating, departmental budgeting, real property planning, maintenance management, general design criteria, and risk management.

\section{Cost Estimating}

As stated in DOE Order $4700 . \mathrm{X}$, the six most frequently used methods of cost estimating are:

a. Bottoms-Up Technique. Generally, a work statement and set of drawings or specifications are used to "take off" material quantities required to accomplish each discrete task performed in accomplishing a given operation of producing an equipment component. From these quantities, direct labor, equipment, and overhead costs are derived and added thereto.

b. Specific Analogy Technique. Specific analogies depend upon the known cost of an item used in prior systems as the basis for the cost of a similar item in a new system. Adjustments are made to known costs to account for differences in relative complexities of performance, design, and operational characteristics.

c. Parametric Technique. 'Parametric estimating requires historical data bases on similar systems or subsystems. Statistical analysis is performed on the data to find correlations between cost drivers and other system parameters, such as design or performance parameters. The analysis produces cost equations or cost estimating relationships which can be used individually or grouped into more complex models. 


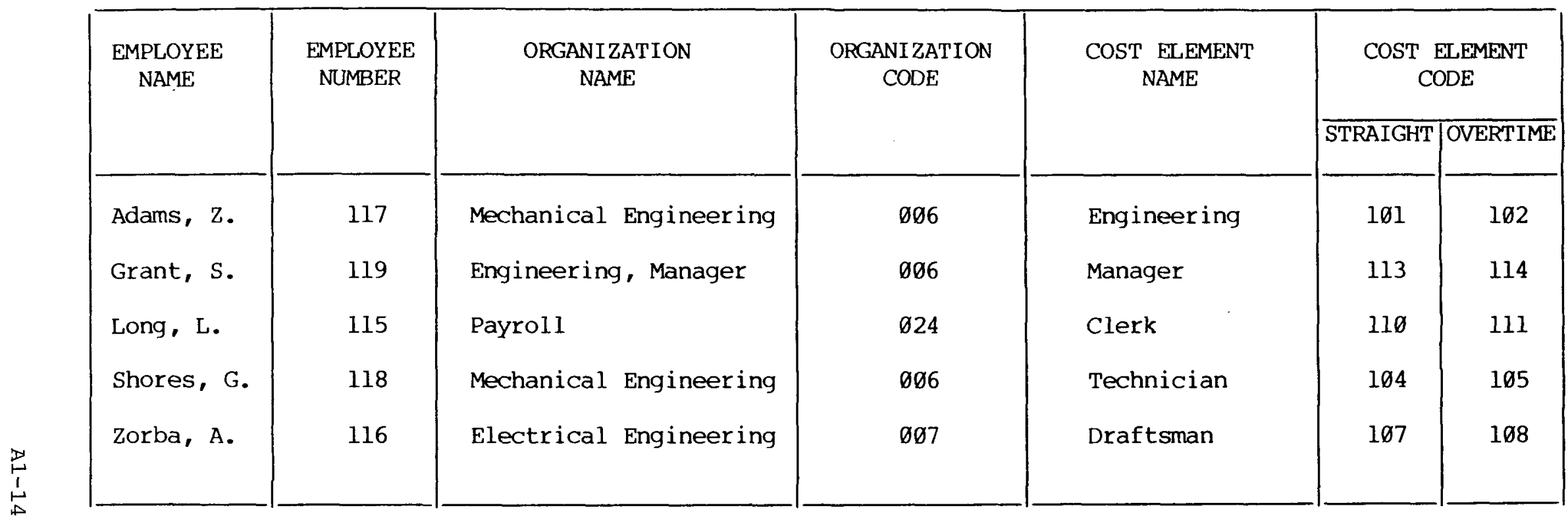

Figure 12. Example Coding Matrix 
d. Cost Review and Update Technique. An estimate is constructed by examining previous estimates of the same project for internal logic, completeness of scope assumptions and estimating methodology. The estimates are then updated to reflect the cost impact of new conditions or estimating approaches.

e. Trend Analysis Technique. A contractor efficiency index is derived by comparing originally projected contract costs against actual costs on work performed to date. The index is used to adjust the cost estimate of work not yet completed.

f. Expert Opinion Technique. This approach may be used when other techniques or data are not available. Several specialists can be consulted reiteratively until a consensus cost estimate is established.

All of these methods depend on knowledge of prior cost experience under similar or related circumstances.

Methods a through $\mathrm{c}$ depend, respectively, on a definition of the work required to produce an equipment component (product), known cost of a similar item (product) used in prior systems and how it differs from the current item, and historical data based on similar systems and subsystems (products). Components, items, and systems are clearly related by the WBS and are defined in the WBS Dictionary. The WBS and WBS Dictionary are, thus, useful tools for cost estimating. Where WBS elements will be budgeted for performance measurement or for performance reporting, basing cost estimates on the WBS elements will facilitate the process.

Methods $d$ and e basically update or adjust, respectively, prior estimates made by one of the other methods.

Method $f$ neither requires nor excludes a product structure, though a product oriented structure is likely to be preferred where a product is to be designed, constructed, or produced. : All estimating methods may, thus, utilize the WBS as the basis for fragmentation of the end product into smaller elements for rollup of estimated costs to the contract and/or project end item level.

2. DOE Budget

a. Draft DOE Order 51ø0, THE BUDGET MANUAL, Chapter I-C, Section 13, Paragraph 3, describes "Preparation of Construction Project Data Sheets." Subparagraph c. (8) defines the methodology for preparing Item 8, "Brief Physical Description of Project." It states that the description should read such that easy correlation can be made with the cost estimate given in Item.10, "Detail of Cost Estimate". Item 8 then goes on to require description of:

(1) Land improvements such as roads, parking lots, fencing. 
(2) Buildings or additions including stories, basement if provided, heating and air-conditioning, drains, shielding, hot cells, ventilation system.

(3) Structures; e.g., pits, tunnels, towers, bunkers, stacks.

(4) Special facilities; e.g., accelerator components, vacuum systems, reactor vessels, purging systems.

(5) Utilities; e.g., sewer, water, power utilities.

(6) Standard equipment; e.g., laboratory furniture and equipment, hoists, machine tools.

Item 10 in turn requires the construction cost estimate to be based on the same items. Since all the required items are typical WBS elements, it is clear that WBS elements should be used not only in cost estimating but in the DOE budget process as well.

b. A WBS can be useful in developing the project funding requirements to be used in the DOE budget process. The mechanism for development of the budget for a project is discussed in DOE Orders 4700 and 5100 . The initial project budget is developed from the conceptual design cost estimate and portrayed on the Project Data Sheet. The cost estimate shown on the Project Data Sheet can be developed along WBS lines or by code of accounts. Figure 13 shows the cost estimate broken out at level 2 of the WBS shown in Figure 2. Figure 14 shows the cost estimate broken out at the primary level of the code of accounts shown on page Al-3. Displaying the cost estimate via the WBS is the preferred method because it provides an estimate against the project's technical objectives, thus permitting tradeoffs between funding requirements and technical performance objectives. At lower levels it also enables objective measurement of technical accomplishment for verifying completion of intermediate events during execution. Note that in the specific case illustrated, the code of accounts tends to detail the site costs while the WBS tends to detail the equipment process systems costs. In this case, it would probably be well to show site costs at the next level down in the WBS to show a more even distribution of costs.

Since the WBS Dictionary, Part I - Index, from the URS (see Appendix D, page D-2), identifies the B\&R number under which funds are allocated to certain WBS elements, cost plans may also be accumulated by $B \& R$ number and summarized through the $B \& R$ structure for Departmentwide funds control.

\section{Real Property}

DOE policy regarding real property planning and maintenance management is stated in two DOE orders. 
1. TITLE AND LOCATION OF PROJECT:

2. PROJECT NO.:

Energistic Unit, Mesquite, Az

$99-14-C$

10. DETAILS OF COST ESTIMATE

ITEM COST TOTAL COST

a. Engineering, Design and Inspection

$\$ 126,432$

b. Construction Costs

306,204

(1) Site

(2) Handling Equipment

(3) Processing Equipment

(4) Maintenance Equipment

(5) Laboratory Equipment

(6) Spares Inventory

(7) Project Support
$\$ 130,124$

23,019

57,206

14,794

11,639

8,181

61,241

c. Total

$\$ 432,636$

Figure 13. Construction Project Data Sheet Cost Estimate By WBS Element Level 2

(a) Real Property and Site Development Planning (Draft DOE 4300.1B)

Draft DOE Order $4300.1 \mathrm{~B}$ applies to site development planning, as well as the acquisition, use, inventory or disposal of all Departmental real property or interests therein. Real property includes land; anything permanently affixed to the land; e.g.., buildings and structures, and anything except process equipment permanently attached to buildings or structures; e.g., plumbing and heating fixtures. Those real property assets that are generated as a result of a project are products that should be included at some level in the WBS assigned to the management organization responsible for their acquisition, use, inventory or disposal. Appropriate coding or use of matrices or crosswalk 
PROJECT DATA SHEET

1. TITLE AND LOCATION OF PROJECT:

2. PROJECT NO.:

Energistic Unit, Mesquite, AZ

99-14-C

10. DETAILS OF COST ESTIMATE

ITEM COST TOTAL COST

a. Engineering, Design and Inspection

$\$ 126,432$

b. Construction Costs

306,204

(1) Land and Land Rights

$\$ 31,352$

(2) Improvements to Land

40,240

(3) Buildings

66,581

(4) Structures

15,410

(5) Utilities

14,692

(6) Special Equipment/Process Systems

102,601

(7) Standard Equipment

35,328

c. Total

$\$ 432,636$

Figure 14. Construction Project Data Sheet Cost Estimate By Code of Accounts Division Level

tables will facilitate the task of assigning the finished components of the project to their correct DOE real property inventory categories, as well as the follow-on real estate and facility management actions that will be required. The Site Development Plan, which is also required-by Draft DOE Order $4300.1 B$, provides useful data about the site, as well as a master plan for its future use and development. As such, it can provide functional relationships and other information which may prove helpful in developing the WBS and any required matrices.

(b) Real Property Maintenance Management (DOE 4330.4)

DOE Order 4330.4, of 3-25-82, provides policy and procedures for real property maintenance programs. Such programs are required 
for all real property acquired and in inventory whether in use or idle. Coordination of maintenance programs with outlay programs is accomplished in part through the development and maintenance of Annual and Long Range Work Plans. Planning may be facilitated by reference to appropriate WBS elements for acquisition and disposal projects which will add to or delete from, respectively, the real property inventory on hand, and in use, and that requiring maintenance.

\section{General Design Criteria}

DOE Order 6430.1, provides general design criteria for use in the acquisition of DOE facilities and establishes responsibilities and authorities for the development and maintenance of general design criteria. Project design criteria are those design criteria specified for a particular project. They must be equal to, or more stringent than, the general design criteria, although deviations are permitted, subject to specified procedures. Since facilities are one or more products on the WBS, the WBS is a convenient mechanism for ensuring that all required design criteria are applied as appropriate throughout the various elements of the project, and for subsequently ensuring through test and inspection that all have been met in actual execution.

\section{Risk Managenent}

DOE does not currently have an order uniquely addressing risk management. However, risk assessment is addressed as a component of project management in DOE 4700. Risk management involves periodic assessment of technical, schedule, and cost plans, and status, to identify potential outcomes, judge their probability of occurrence, and make consistently disciplined economic decisions spanning the three variables. If properly constructed, the WBS is uniquely capable of supporting technical, schedule, and cost data on an integrated, consistent basis. 


\section{APPENDIX A}

DOE PROJECT MANAGEMENT SYSTEM REFERENCE DOCUMENTS

$A-1$ 
1. ORDERS

a. DOE 1332.IA, UNIFORM REPORTING SYSTEM

Establishes DOE policy for establishing reporting requirements for contracts, loans, and loan guarantees, and provides forms, formats, instructions, and procedures for reporting essential management information including reporting by WBS.

b. DOE 2250.1B, COST AND SCHEDULE CONTROL SYSTEMS CRITERIA FOR CONTRACT PERFORMANCE MEASUREMENT.

Establishes DOE policy for applying and using the cost and Schedule Control Systems Criteria (CSCSC) on DOE major system acquisition, major, and other projects. The CSCSC require use of a WBS.

c. DOE 4306.1B, REAL PROPERTY AND SITE DEVELOPMENT PLANNING

To establish Departmentwide policies and procedures for planning the development and utilization of sites and their facilities and for the acquisition, use, inventory, and disposal of real property or interests therein.

d. DOE 4330.4 , REAL PROPERTY MAINTENANCE MANAGEMENT

To provide policy and procedures for the establishment of programs for the maintenance and repair of DOE real property.

e. DOE 47øø.X, PROJECT MANAGEMENT SYSTEM

Establishes the DOE project management system and provides implementing instructions, formats, and procedures, and sets forth the principles and requirements which govern the development, approval, and execution of DOE's outlay program acquisitions including use of the WBS.

f. DOE 6430.1, GENERAL DESIGN CRITERIA

Establishes policies and objectives, responsibilities and authorities, procedures and requirements related to use of general design criteria.

2. INFORMATION PAMPHLETS

a. DOE/MA-0155, COST AND SCHEDULE CONTROL SYSTEMS CRITERIA FOR CONTRACT PERFORMANCE MEASUREMENT - INFORMATION PAMPHLET.

Provides a narrative and graphic illustration of the basic concepts and general requirements of CSCSC including organization of work using the WBS and integration with the organization structure.

b. DOE/MA-ø191, UNIFORM REPORTING SYSTEM - INFORMATION PAMPHLET

Provides a narrative and graphic illustration of the features and use of the Uniform Reporting System including reporting by WBS. 
c. DRAFT DOE 5Iø0, - BUDGET MANUAL

Establishes the policy, procedures, and responsibilities of DOE for budget formulation, execution, review, and analysis in accordance with executive, legislative, and internal management requirements.

3. GUIDES

a. DOE/MA- 0063 , Volume 6, COST GUIDE - COST ESTIMATING METHODS AND TECHNIQUES.

Illustrates how quantity takeoff estimating is performed and how statistics can be applied to obtain parametric cost estimates.

b. DOE/MA- 0195, COST AND SCHEDULE CONTROL SYSTEMS CRITERIA FOR CONTRACT PERFORMANCE MEASUREMENT - SUMMARY DESCRIPTION.

Provides an overview of the DOE criteria approach for contract performance measurement. It was prepared to assist both DOE and industry personnel in understanding and using the CSCSC approach properly. Includes chapter on WBS.

C. DOE/MA- 6203, COST AND SCHEDULE CONTROL SYSTEMS CRITERIA FOR CONTRACT PERFORMANCE MEASUREMENT - IMPLEMENTATION GUIDE

Provides uniform guidance for implementation of the CSCSC. It assists both DOE and contractor representatives in fulfilling their responsibilities for meeting $\operatorname{CSCSC}$ requirements which include use of a WBS.

d. DOE/MA-0221, COST AND SCHEDULE CONTROL SYSTEMS CRITERIA FOR CONTRACT PERFORMANCE MEASUREMENT - CONTRACTOR REPORTING/DATA ANALYSIS GUIDE.

Provides suggested techniques for analyzing contractor cost and schedule data reported by WBS and organization structures to give insight into current contract performance status and help forecast future contract performance.

4. OTHER GOVERNMENT AGENCY PUBLICATIONS

a. Department of Defense, MIL-STD-881A, "Work Breakdown Structure for Defense Material Items," 1975 
APPENDIX B

TYPICAL PROJECT SUMMARY WORK BREAKDOWN STRUCTURES

1. Nuclear Generating Plant

2. Fuel Processing Plant

3. Test Facility

4. Test Reactor Modification Project

5. Accelerator Project at an Existing Site 


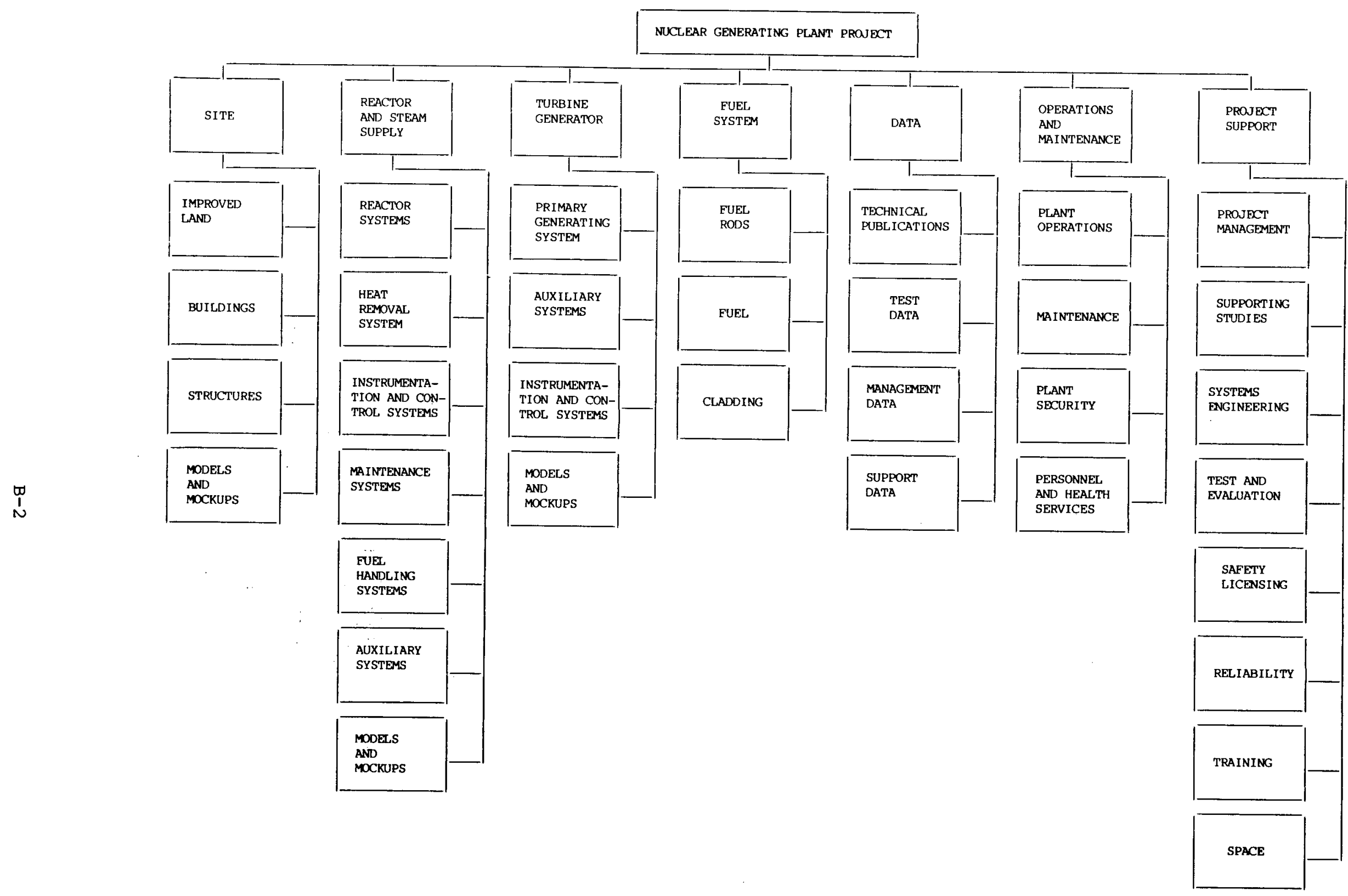

1 - TYPICAL PROJECT SUMMARY WORK BREAKDOWN STRUCTURE FOR A NUCLEAR GENERATING PLANT PROJECT 


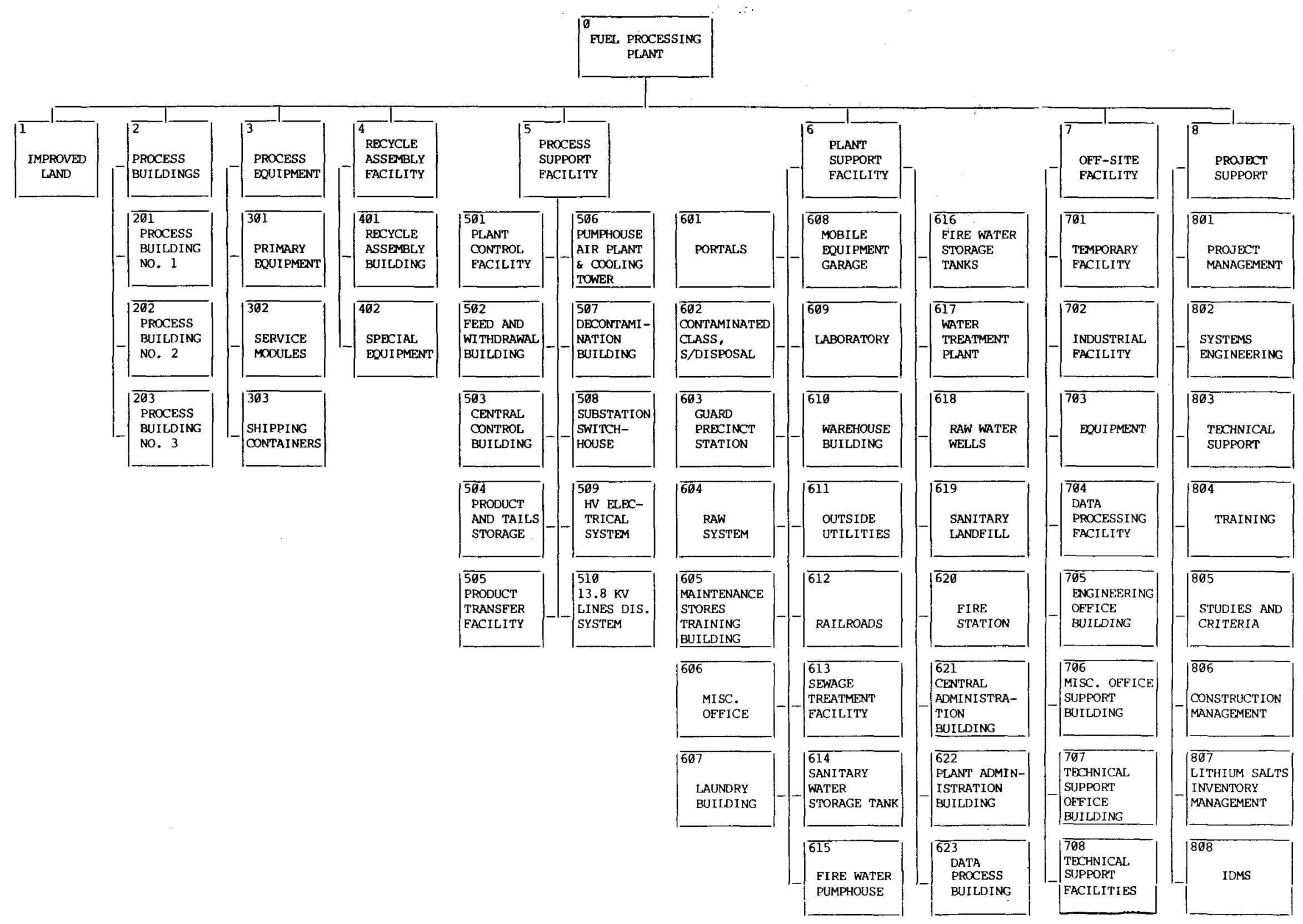

2 - TYPICAL PROJECT SUMMARY WORK BREAKDOWN STRUCTURE FOR A FUEL PROCESSING PLANT 


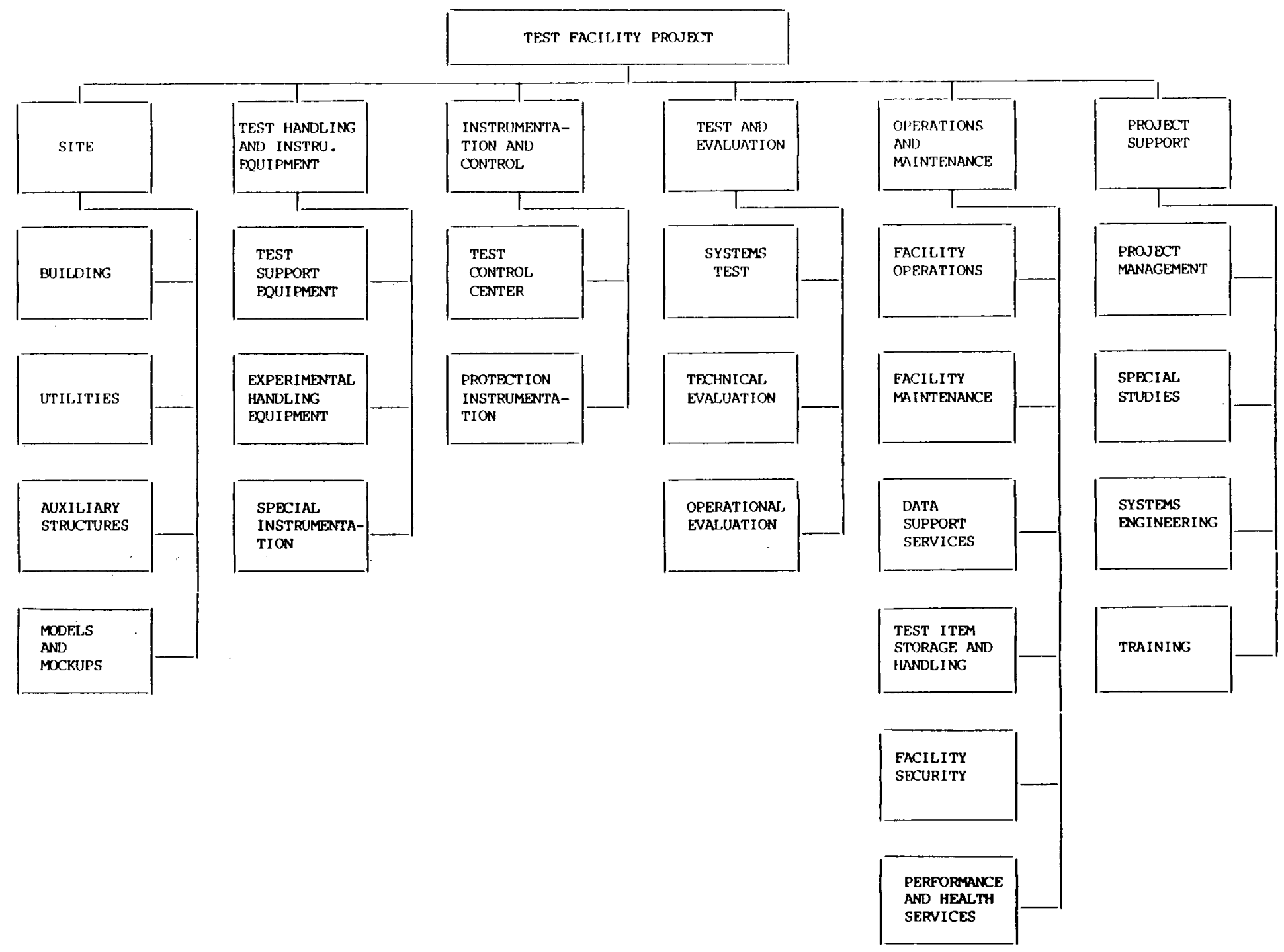

3 - TYPICAL PROJECT SUMMARY WORK BREAKDOWN STRUCTURE FOR A TEST FACILITY PROJECT 


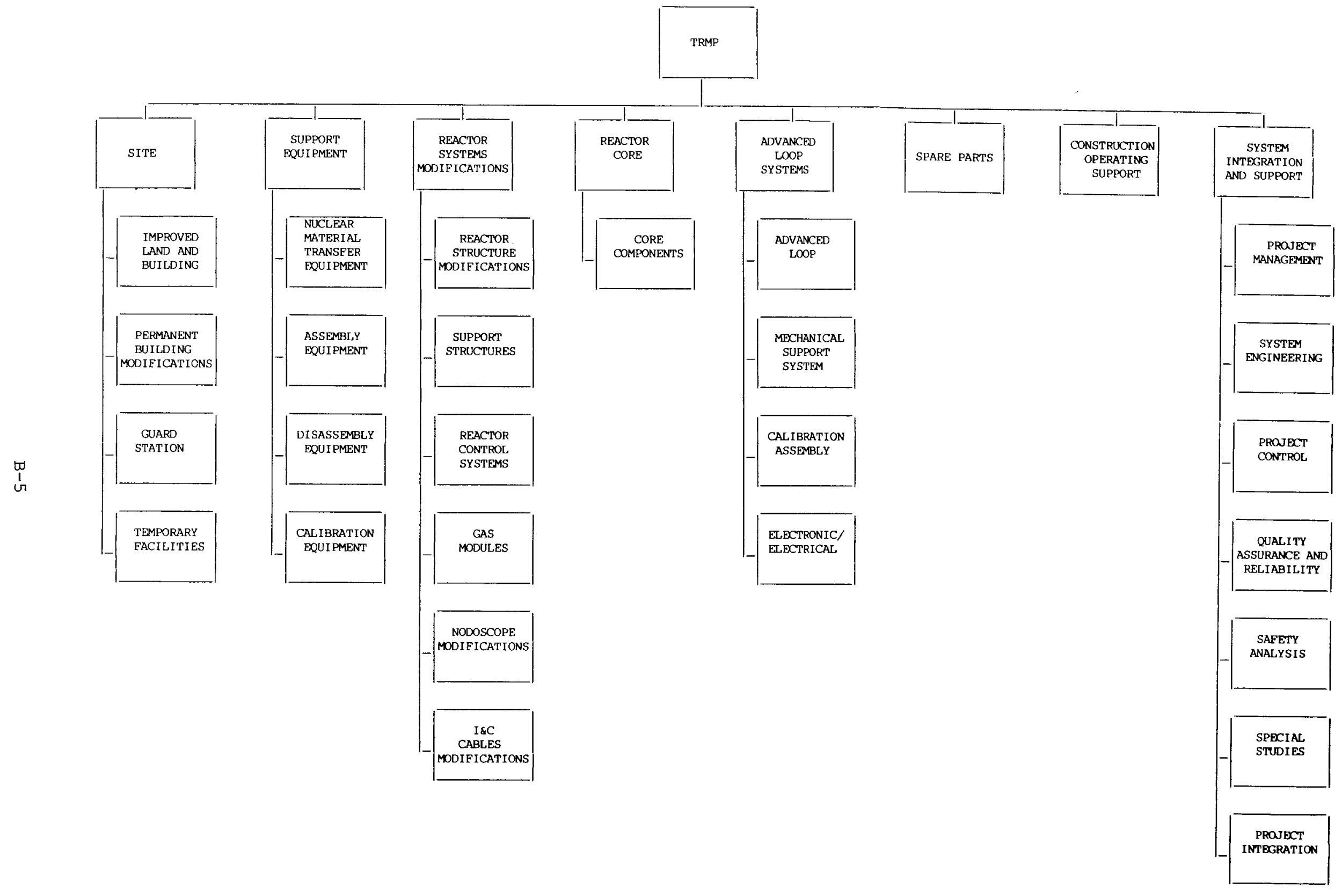

4 - PROJECT SUMMARY WORK BREAKDOWN STRUCTURE FOR

A TEST REACTOR MODIFICATION PROJECT 


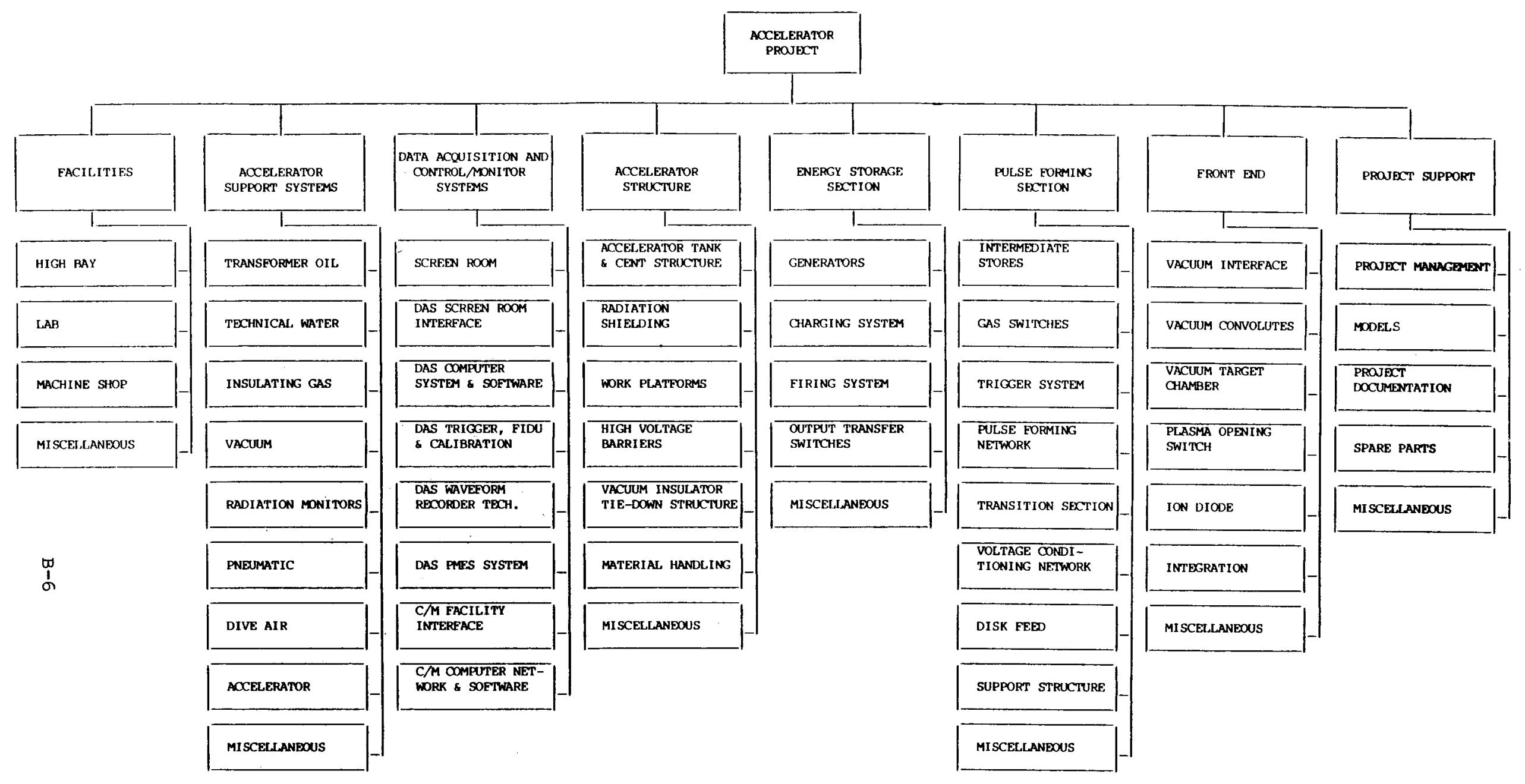

5 - TYPICAL PROJECT SUMMARY WORK BREAKDOWN STRUCTURE FOR AN ACCELERATOR PROJECT AT AN EXISTING SITE 


\section{APPENDIX C}

WORK BREAKDOWN STRUCTURE DICTIONARY

1. Work Breakdown Structure Dictionary Part I - Index (DOE Form 1332.10)

2. Work Breakdown Structure Dictionary Part II - Element Definition

(DOE Form 1332.11) 


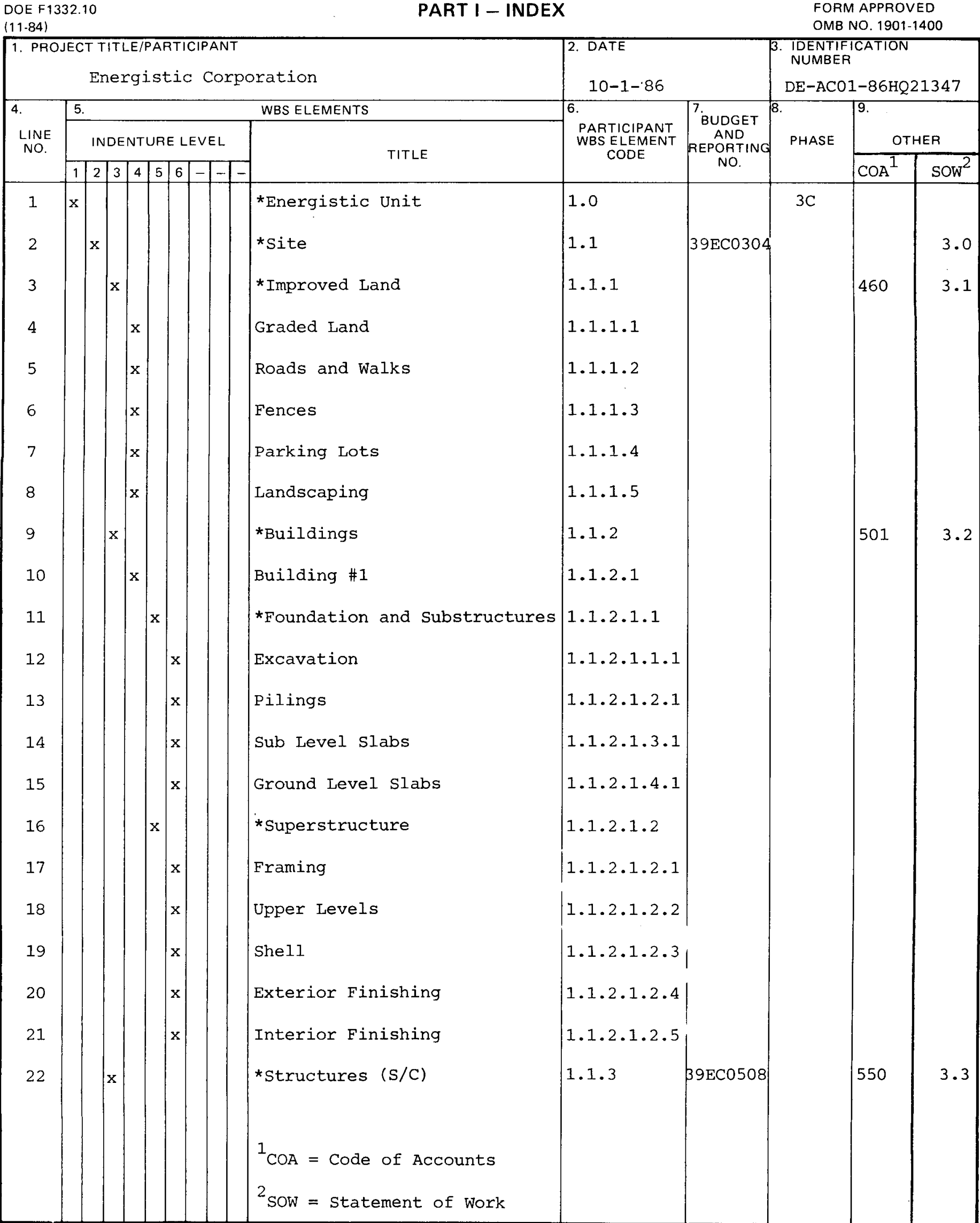




\section{WORK BREAKDOWN STRUCTURE DICTIONARY PART I - INDEX}

\section{PURPOSE}

The work breakdown structure index lists the preliminary work breakdown structure elements extended to the lowest level required. Complete only applicable blocks. Specific project requirements may be added as needed.

\section{INSTRUCTIONS}

Item 1. Enter project title and name of participant.

Item 2. Enter date of preparation.

Item 3. Enter applicable contractual agreement number.

Item 4. Enter sequential numbers to identify each entry.

Itam 5. Enter the work breakdown structure element title and an " $X$ " to reflect the level (e.g., level 1 is the contract); level 2 , 3 , etc., are successively lower indentures of the contract work breakdown structure). Enter an asterisk (") before the title of each element to be reported. Enter a parenthetic $(s / c)$ following each subcontract element title.

Item 6. Enter the code devised by the participant for internal identification of the work breakdown structure element.

Item 7. Enter the appropriate Budget and Reporting (B\&R) number.

Item 8. Enter the appropriate designator from the table below to identify the project phase. (See DOE 5700.3B, MAJOR SYSTEM ACQUISITION PROCEDURES, Attachment 3 , for reference):

\author{
1 = Basic Research, Applied Research, or Technology \\ or Exploratory Development \\ 2 = Advanced Development \\ 3 = Engineering Development \\ $4=$ Demonstration \\ $5=$ Operation/Production
}

Since construction may take place under all of the above phases a second code, " $C$ ", may be necessary le.g., a constrution project occuring during the "engineering development" phase would be designated ' $3 \mathrm{C}$ ').

Item 9. Add columns as required to cross-reference the work breakdown structure element to other pertinent documents. For example, columns may be added for System Design Description Number, Configuration Item Number, Statement of Work Number, etc., and the applicable reference entered. 


\section{WORK BREAKDOWN STRUCTURE DICTIONARY PART II - ELEMENT DEFINITION}

\begin{tabular}{|c|c|c|}
\hline $\begin{array}{l}\text { 1. PROJECT TITLE/PARTICIPANT } \\
\text { Energistic Corporation }\end{array}$ & $\begin{array}{l}\text { 2. DATE } \\
10-1-86\end{array}$ & $\begin{array}{l}\text { 3. IDENTIFICATION NUMBER } \\
\text { DE-ACO } 1-86 \mathrm{HQ} 21347\end{array}$ \\
\hline $\begin{array}{l}\text { 4. WBS ELEMENT CODE } \\
1.1 .1\end{array}$ & $\begin{array}{l}\text { 5. WBS ELEMENT TITLE } \\
\text { Improved Land }\end{array}$ & \\
\hline $\begin{array}{l}\text { 6. INDEX LINE NO. } \\
3\end{array}$ & $\begin{array}{l}\text { 7. REVISION NO. AND AUTHORIZATION } \\
\text { N/A }\end{array}$ & $\begin{array}{l}\text { 8. DATE } \\
\text { N/A }\end{array}$ \\
\hline
\end{tabular}

9. APPROVED CHANGES

$\mathrm{N} / \mathrm{A}$

10. SYSTEM DESIGN DESCRIPTION

Number: $48 \mathrm{E} 32$ (1.1.1)

Title: Improved Land

11. BUDGET AND REPORTING NUMBER

2. ELEMENT TASK DESCRIPTION

a. Cost Content Civil Engineering Labor

Construction Labor

Purchased Material

Subcontracted Efforts:

$\mathrm{N} / \mathrm{A}$

Transportation

Warehousing

Equipment Rental

Overhead

Cost of Money

$\mathrm{G} \& \mathrm{~A}$

b. Technical Content

74.2 acre triangular graded, cleared and landscaped plot at N.E. junction of Ronald Reagan Blvd. and Jimmy Carter Avenue, and adjoining the Mohawk River on the remaining side. Includes 18.1 miles chain link perimeter fence for industrial grade security, with 2 electrically powered gates to give vehicle and pedestrian access to both adjoining roads. Includes 5.8 acre rectangular asphalt lot to park 20 passenger vehicles, 2.3 miles asphalt roadway to link parking lot with both adjoining roads, roadway curbs with drains to channel runoff to river, and 3.2 miles concrete sidewalk to connect gates and buildings.

c. Work statement

Note: Most major work is performed at lower WBS levels.

Engineering: Prepare integrating design documents;

Monitor and evaluate integration of lower level element construction;

Provide integrating design changes as required;

Prepare integrated as-built drawings.

Construction: Integrate lower level elements. 


\section{WORK BREAKDOWN STRUCTURE DICTIONARY PART II - ELEMENT DEFINITION}

\section{PURPOSE}

Part II describes the work breakdown structure elements contained in the Index and their relationship to design and funding documents. Complete only applicable blocks. Specific project requirements may be added as needed.

\section{INSTRUCTIONS}

Item 1. Enter project title and participant name.

Item 2. Enter date of preparation.

Item 3. Enter the identification number.

Item 4. Enter the work breakdown structure element code from Column 6, Part I - Index.

Item 5. Enter the work breakdown structure element number.

Item 6. Enter index line number.

Item 7. Enter the identifier of the current revision and reference the authorizing document.

Itam 8. Enter date of current revision identified in Item 7.

Itam 9. Enter the identifier and short title of previously approved changes to the work breakdown structure element.

Item 10. Enter the system design description number and title or other appropriate system specification identification pertaining to the work breakdown structure element.
Item 11. Enter the appropriate Budget and Reporting Number.

Itam 12. Element Task Description

a. Describe the type of organizational entities and/or elements of costs charged to the work breakdown structure element le.g., Construction Labor, Engineering Labor, Electrical Cable, Vendor Tooling, Subcon. tracted Effort, Computer Operation, Travel, Printing, etc.).

b. Describe the technical content le.g., heat transport system), the components included (e.g., instrumentation and controls), their relationships to each other (e.g., operating temperatures and pressures), and how they support other work breakdown structure elements (e.g., reactor core).

c. Describe the functional activity or service necessary to make the product or to accomplish the work objectives of the work breakdown structure element (planning, designing, fabricating, testing, etc.). 
APPENDIX D

UNIFORM REPORTING SYSTEM

REPORTING REQUIREMENTS CHECKLIST

DOE FORM 1332.1

D-1 


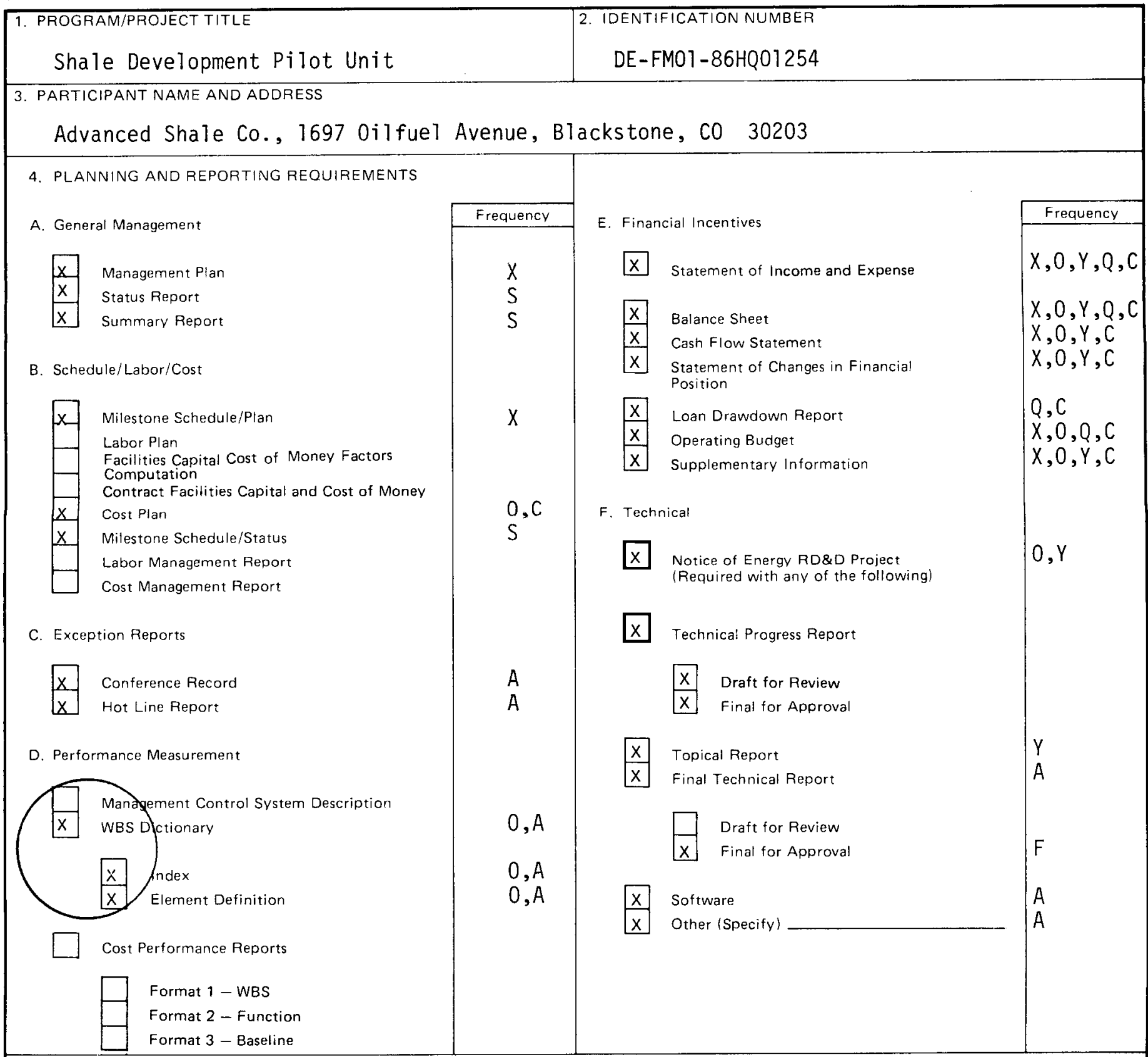

\section{FREQUENCY CODES}
A - As Required
M - Monthly
$S$ - Semi-Annually
C - Change to Contractual Agreement
O - Once After Award
$X$ - With Proposal/Bid/Application or with Significant Changes
F - Final (end of effort)
Q - Quarterly
$Y$ - Yearly or Upon Renewal of Contractual Agreement

6. SPECIAL INSTRUCTIONS (ATTACHMENTS)
$\mathrm{X}$ Report Distribution List/Addressees
Reporting Elements
Due Dates
Work Breakdown Structure
Other 


\section{REPORTING REQUIREMENTS CHECKLIST}

\section{PURPOSE}

The checklist identifies and communicates additional reporting requirements which are not otherwise set forth in DOE contractual agreement. It will be included as part of the contractual agreements. The checklist will be completed for each contract or financial incentives agreement. If necessary, special instructions may be appended to modify the checklist to adapt it to specific situations.

\section{INSTRUCTIONS}

Item 1. Enter the title of the project as indicated in the procurement request, contract, interagency agreement, initiating memorandum, or official award, as appropriate.

Item 2. Enter the identification number of the procurement request, contract award, or financial incentives agreement, as appro. priate.

Item 3. Enter the name and address of the participant.

Item 4. Check spaces to indicate plans and reports selected. For each reporting requirement selected, indicate the frequency of delivery using one of the frequency codes from Item 5 . The addressees to whom reports will be sent and the total number of copies required will be referenced in an attached coded distribution list.
Note: Frequency codes represent specific reporting fre quencies for each selected report. The frequencies are recommended in the solicitation and negotiated prior to award. The number of copies required and the addressees are similarly finalized prior to award.

Item 5. This item lists the possible frequency codes to be applied in the selection of reporting requirements.

Item 6. Attach special instructions as necessary. Check the appropriate box(es).

Item 7. Signature of person preparing checklist and the date prepared.

Item 8. Signature of person reviewing the checklist and date reviewed. 
APPENDIX E

DEVELOPMENT OF A PROJECT SUMMARY WBS

E-1 


\section{INTRODUCTION}

The following sections briefly summarize the documented basis for development of a Project Summary WBS for a (fictitious) Magnetically Pulsed Plasma Cannon Test Facility Project. The Project Sumary WBS evolved from an analysis of the project objectives, the functional design criteria, and the procurement strategy.

\section{PROJECT OBJECTIVE}

The project consists of the design, fabrication, construction, test and startup of a Magnetically Pulsed Plasma Cannon Test Facility, that will enable essentially steady state (10-30 seconds) plasma physics experiments to be conducted in a magnetic triple mirror geometry in an environmentally acceptable manner.

\section{PLANT AND EQUIPMENT FUNCTIONAL DESIGN CRITERIA}

The equipment will be designed to produce the following measurable center cell plasma characteristics:

- quality of confinement $=6 \times 10^{-3} \mathrm{sec} \mathrm{cm}^{-3}$

- average ion energy $=17 \mathrm{kev}$.

The equipment will include three steady state superconducting magnetic reflection systems with 18 center cell solenoid coils, three sets of anicell coils - including three high field insert coils and two sets of transition coils.

As regulated, conditioned high voltage electrical power system will include $120 \mathrm{kv}$ sources to drive the neutral beam injectors, the sustaining neutral beam sources, the injection system, and the passing particle barrier beams.

Vacuum vessel and pumping equipment will produce initial pressure $10^{-8}$ torr in the vacuum vessel, preshot pressure of $610^{-8}$ torr, and maintain plasma region pressure of $31 \emptyset^{-6}$ torr during a 30 second pulse. Helium liquification and refrigeration and liquid nitrogen storage and distribution systems will support cryogenic requirements.

Additional equipment includes data acquisition and processing systems, process control system, safety interlock system, and a $230 \mathrm{kv}$ to $13.8 \mathrm{kv}$ power system capable of supplying $250 \mathrm{mw}$ on a 10 percent duty cycle.

Conventional facilities required include a building to house the equipment, the control room, and the diagnostics room, an office building to house 250 permanent staff, and two small buildings for light laboratory work, maintenance, spares, and technician support. Environmental and safety studies will be required. 
4. PROCUREMENT STRATEGY

Industrial components and systems will be obtained on a competitive basis using firm fixed price contracts where feasible. Cost type procurements will be used as appropriate in R\&D. Conventional construction will employ advertised, competitive, fixed price procurement. A detailed procurement plan is in the process of being developed. 


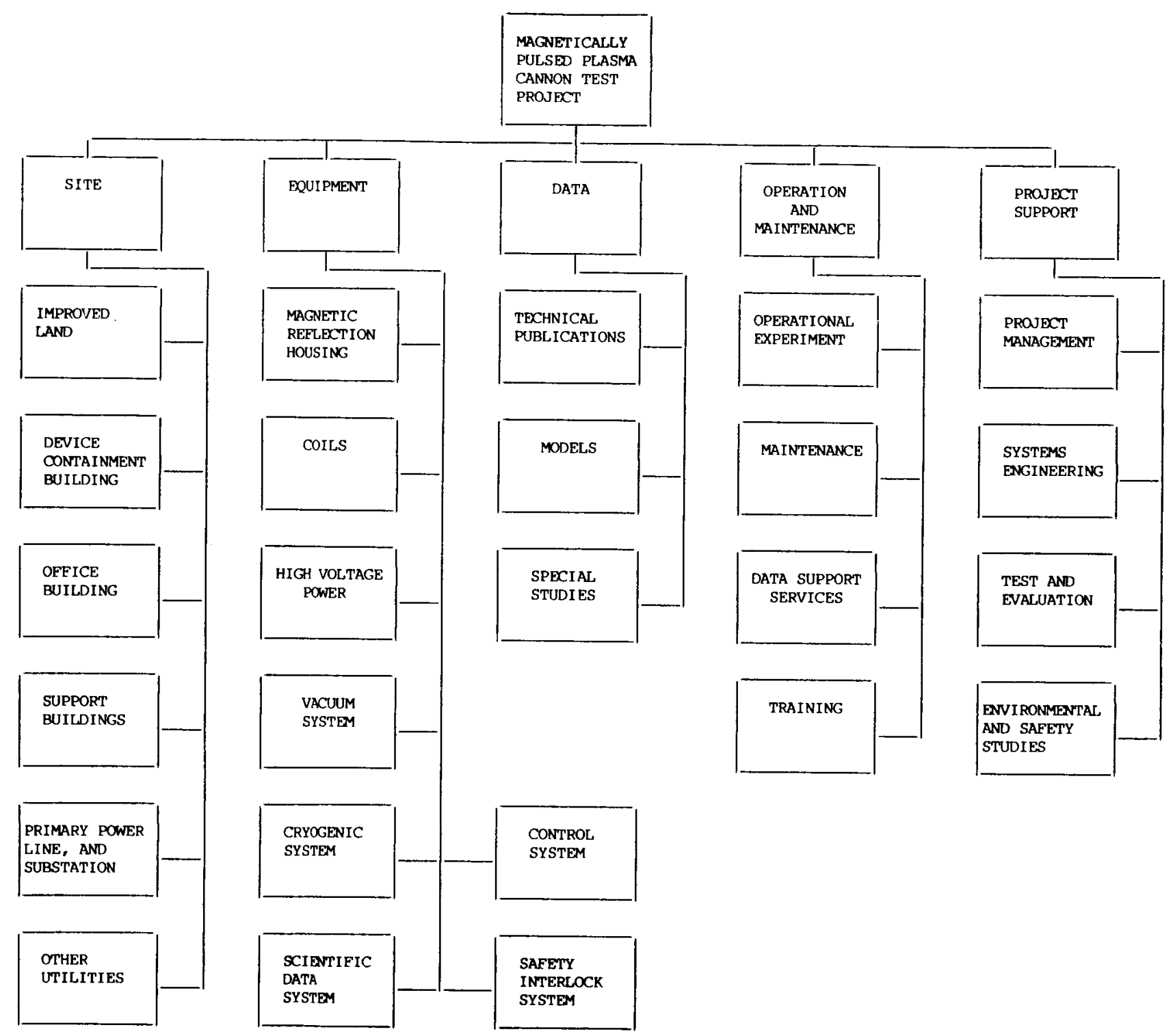

PROJECT SUMMARY WORK BREAKDOWN STRUCTURE FOR

A (FICTIONAL) MAGNETICALLY PULSED PLASMA CANNON TEST PROJECT 